\title{
STREAMLINED APPROACH FOR ENVIRONMENTAL RESTORATION PLAN FOR CORRECTIVE ACTION UNIT 134: ABOVEGROUND STORAGE TANKS, NEVADA TEST SITE, NEVADA
}

\author{
U.S. Department of Energy \\ National Nuclear Security Administration \\ Nevada Site Office
}

Controlled Copy No.:

Revision: 0

May 2008 
THIS PAGE INTENTIONALLY LEFT BLANK 


\section{STREAMLINED APPROACH FOR ENVIRONMENTAL RESTORATION PLAN FOR CORRECTIVE ACTION UNIT 134: ABOVEGROUND STORAGE TANKS, NEVADA TEST SITE, NEVADA}

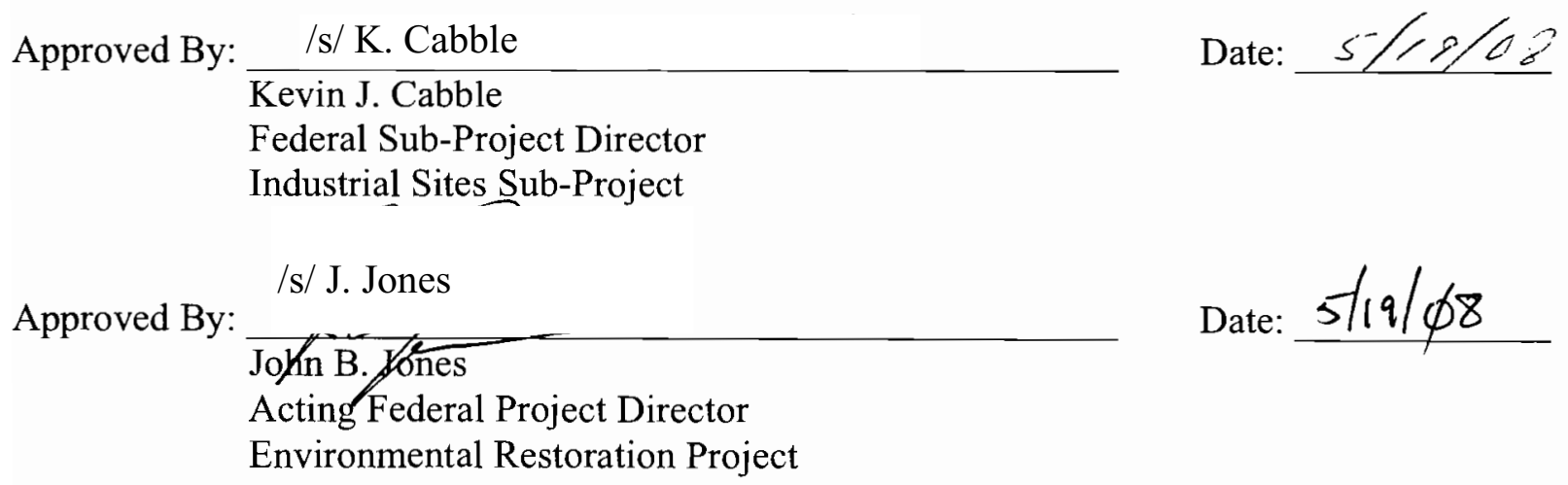


THIS PAGE INTENTIONALLY LEFT BLANK 


\section{TABLE OF CONTENTS}

EXECUTIVE SUMMARY ...................................................................

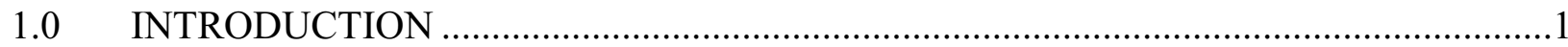

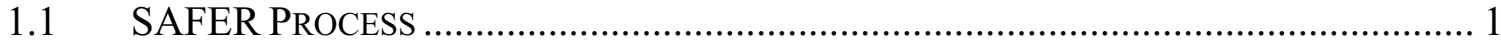

1.2 SUMMARY OF PROPOSED CORRECTIVE ACTIONS ..................................................... 3



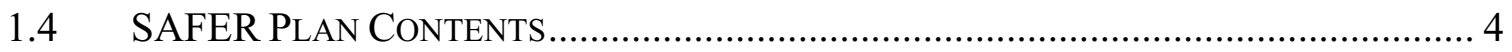

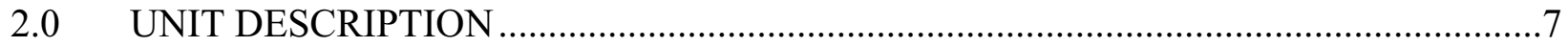

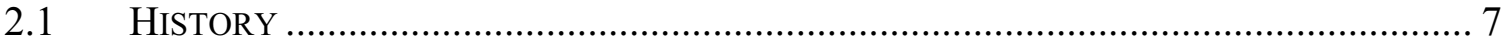

2.1.1 CAS 03-01-03, Aboveground Storage Tank ..............................................

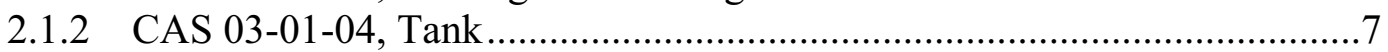

2.1.3 CAS 15-01-05, Aboveground Storage Tank..............................................

2.1.4 CAS 29-01-01, Hydrocarbon Stain......................................................

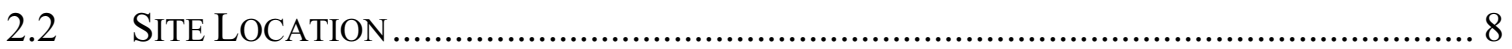

2.2.1 CAS 03-01-03, Aboveground Storage Tank............................................

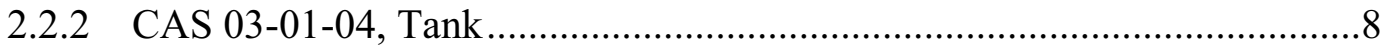

2.2.3 CAS 15-01-05, Aboveground Storage Tank ..............................................

2.2.4 CAS 29-01-01, Hydrocarbon Stain ...................................................

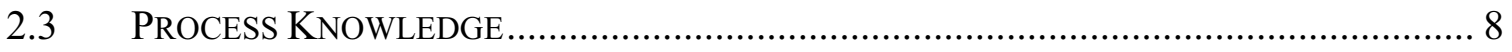

2.3.1 CAS 03-01-03, Aboveground Storage Tank.............................................8

2.3.2 CAS 03-01-04, Tank ……....................................................................

2.3.3 CAS 15-01-05, Aboveground Storage Tank.............................................

2.3.4 CAS 29-01-01, Hydrocarbon Stain.........................................................

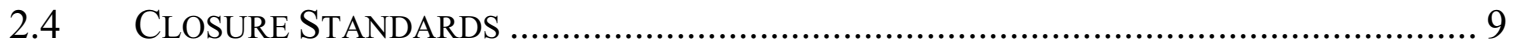

2.4.1 CAS 03-01-03, Aboveground Storage Tank...........................................9

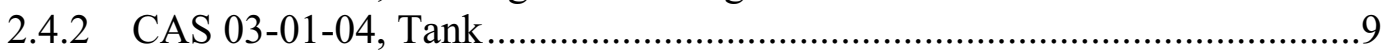

2.4.3 CAS 15-01-05, Aboveground Storage Tank..............................................11

2.4.4 CAS 29-01-01, Hydrocarbon Stain...............................................................11

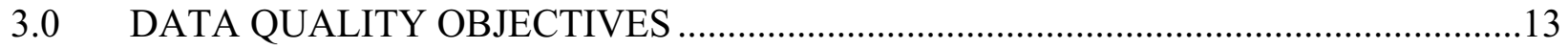

$3.1 \quad$ SUMMARY OF DQO ANALYSIS .................................................................... 13

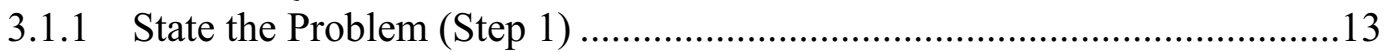

3.1.1.1 CSM .......................................................................... 13

3.1.2 Identify the Goal of the Study (Step 2) ...................................................18

3.1.3 Identify Information Inputs (Step 3) …………..................................18

3.1.3.1 Information Needs ……………………….......................... 18

3.1.3.2 Sources of Information ......................................................... 18

3.1.4 Define the Boundaries of the Study (Step 4) .........................................23

3.1.4.1 Population of Interest.......................................................... 23

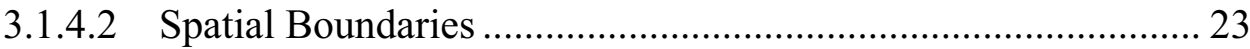

3.1.4.3 Time Constraints ................................................................... 23

3.1.4.4 Practical Constraints ............................................................... 27

3.1.5 Develop the Analytic Approach (Step 5) ………....................................27

3.1.5.1 Population Parameters ……………………………………...... 27 


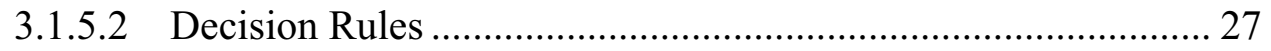

3.1.5.3 Action Levels ...................................................................... 28

3.1.5.4 Measurement and Analysis Sensitivity ……………………....... 28

3.1.6 Specify Performance or Acceptance Criteria (Step 6) ..............................28

3.1.6.1 Decision Errors ...................................................................... 30

3.1.6.1.1 False Rejection (False Positive) Decision Error .......... 30

3.1.6.1.2 False Acceptance (False Negative) Decision Error .... 30

3.1.7 Develop the Plan for Obtaining Data (Step 7) ......................................... 31

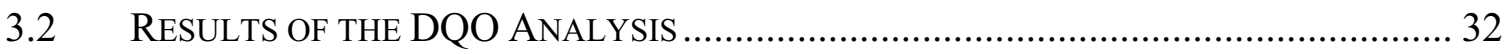

3.2.1 Action Level Determination and Basis .....................................................32

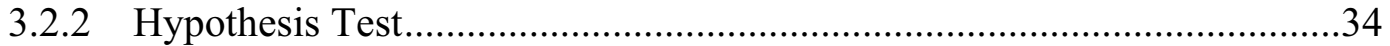

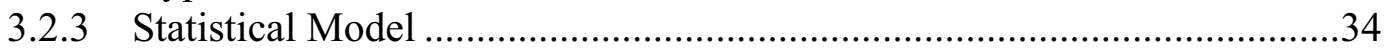

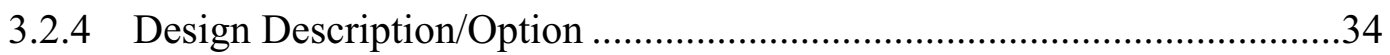

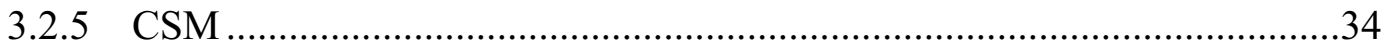

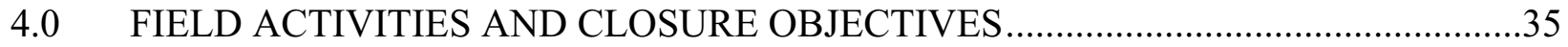

4.1 Contaminants of Potential CONCERn........................................................ 35

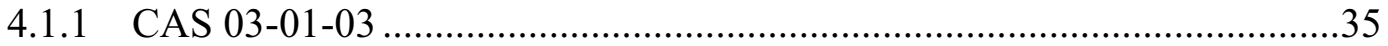

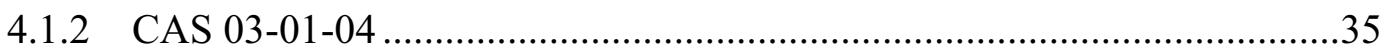

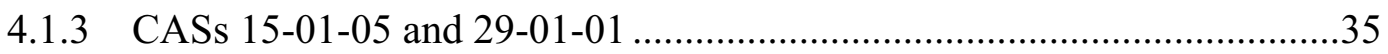

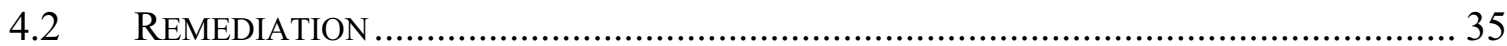

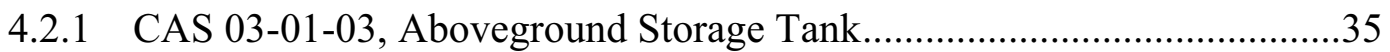

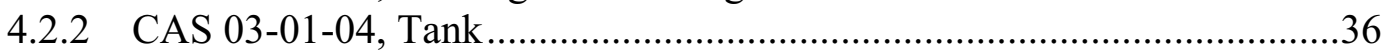

4.2.3 CAS 15-01-05, Aboveground Storage Tank................................................36



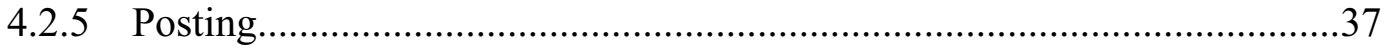

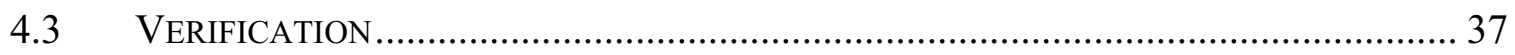

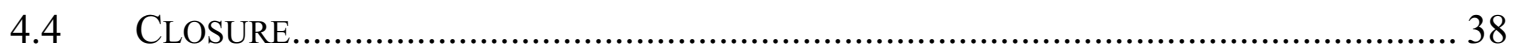

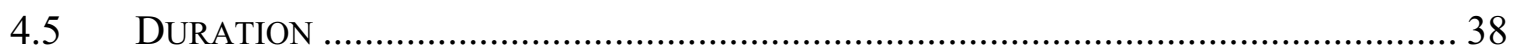

5.0 REPORTS AND RECORDS AVAILABILITY ……………………………..............

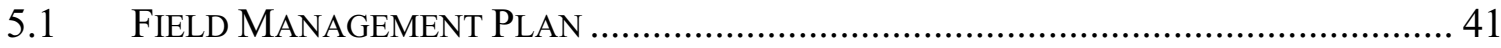

5.2 NATIONAL ENVIRONMENTAL POLICY ACT CHECKLIST ............................................. 41

5.3 DAILY FIELD REPORTS............................................................................. 41

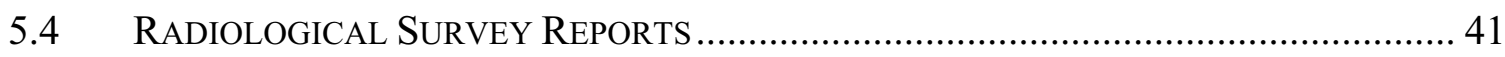

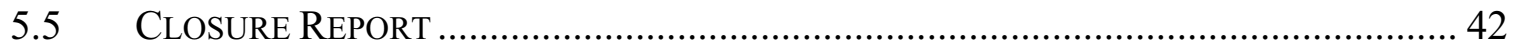

6.0 INVESTIGATION/REMEDIATION WASTE MANAGEMENT …………....................43

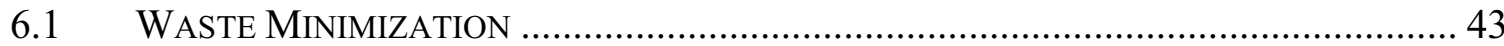

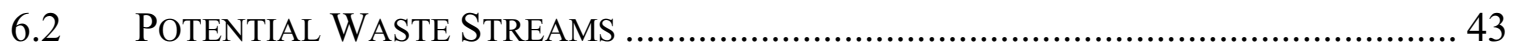

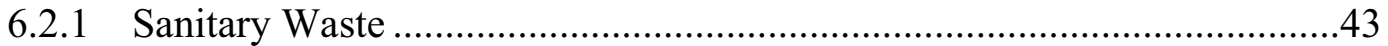

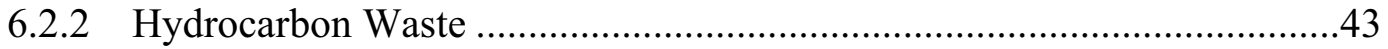

7.0 QUALITY ASSURANCE/QUALITY CONTROL ………….....................................45

7.1 SAMPLE COLLECTION ACTIVITIES......................................................................... 45

7.2 APPLICABLE LABORATORY/ANALYTICAL DATA QUALITY INDICATORS................. 45 


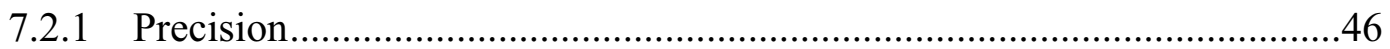

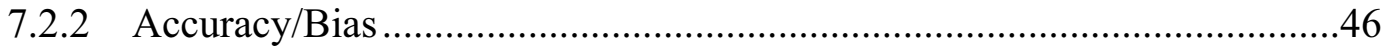

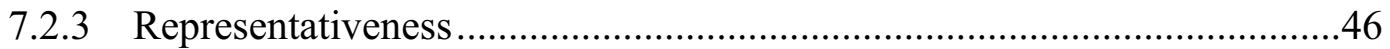

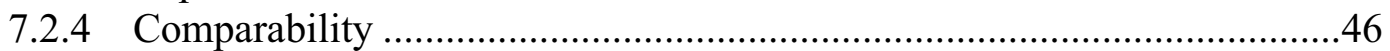

7.2.5 Completeness .............................................................................4 46

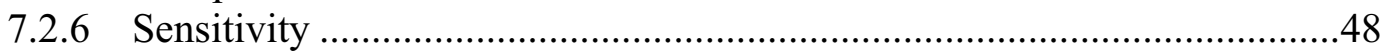

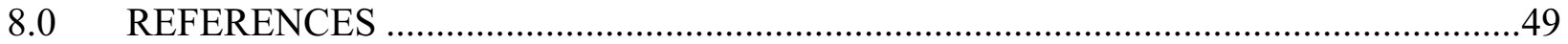

LIBRARY DISTRIBUTION LIST

\section{FIGURES}

Figure 1. Location of CAU 134: AbOVEgRound Storage TANKS ......................................... 2

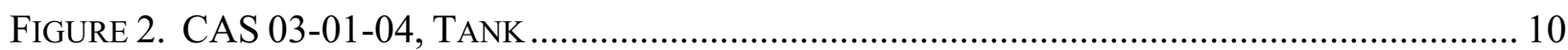

Figure 3. Primary CONCEPTUAL Site MOdel FOR CASs 03-01-03 \& 15-01-05, AND Alternate

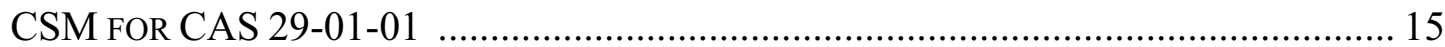

Figure 4. Primary CONCEPtuAl Site Model fOR CAS 29-01-01 AND Alternate CSM for

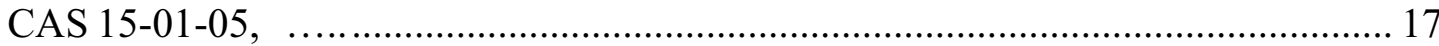

Figure 5. CAS 03-01-03, AbOVEground StORAGE TANK, CAS BOUNDARY ........................... 24

Figure 6. CAS 15-01-05, ABOVEGROUND StORAGE TANK, CAS BOUNDARY ........................... 25

Figure 7. CAS 29-01-01, Hydrocarbon Stain, CAS Boundary AND Proposed SAMPLE

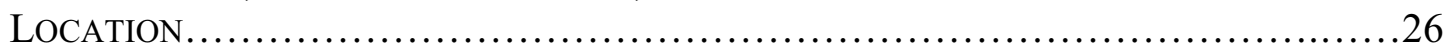

Figure 8. DECISION FLOWCHART FOR CASs 15-01-05 AND 29-01-01 ..................................... 33

\section{TABLES}

TABLE 1. INFORMATION NEEDS FOR DECISION RESOLUTION ................................................ 19

TABle 2. Chemical Components of Diesel And Associated PRGs .................................... 29

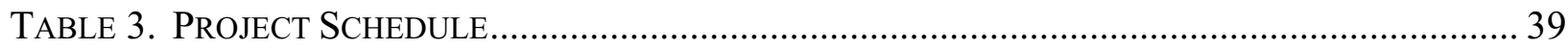

TABLE 4. LABORATORY/ANALYTICAL DATA QUALITY INDICATORS ........................................ 47

\section{APPENDICES}

ApPendiX A. Project OrganizATION 
SAFER Plan - CAU 134

Section: Table of Contents

Revision: 0

Date: May 2008

THIS PAGE INTENTIONALLY LEFT BLANK 


\section{ACRONYMS AND ABBREVIATIONS}

AST aboveground storage tank

BMP best management practice

CAS Corrective Action Site

CAU Corrective Action Unit

COC contaminant of concern

COPC contaminant of potential concern

CR Closure Report

CSM conceptual site model

DOE/NV U.S. Department of Energy, Nevada Operations Office

DQI data quality indicator

DQO data quality objective

EPA U.S. Environmental Protection Agency

ER Environmental Restoration

FAL final action level

FFACO Federal Facility Agreement and Consent Order

FMP Field Management Plan

$\mathrm{ft} \quad$ foot (feet)

FY fiscal year

gal gallon(s)

JHA job hazard analysis

LANL Los Alamos National Laboratory

M\&OC Management and Operations Contractor

$\mathrm{mg} / \mathrm{kg} \quad$ milligram(s) per kilogram

mi mile

NAC Nevada Administrative Code

NDEP Nevada Division of Environmental Protection

NEPA National Environmental Policy Act

NNSA/NSO U.S. Department of Energy, National Nuclear Security Administration Nevada Site Office

NNSA/NV U.S. Department of Energy, National Nuclear Security Administration Nevada Operations Office

NTS Nevada Test Site

PAL preliminary action level 


\section{ACRONYMS AND ABBREVIATIONS (continued)}

PRG preliminary remediation goal

QA quality assurance

QAPP Quality Assurance Project Plan

QC quality control

RadCon Radiological Control

REECo Reynolds Electrical and Engineering Company, Inc.

REOP Real Estate/Operations Permit

SAFER Streamlined Approach for Environmental Restoration

SDG sample delivery group

SSHASP Site-Specific Health and Safety Plan

SVOC semi-volatile organic compound

TPH total petroleum hydrocarbons

UR use restriction

VOC volatile organic compound

$\% \mathrm{R} \quad$ percent recovery 


\section{EXECUTIVE SUMMARY}

This plan covers activities associated with Corrective Action Unit (CAU) 134 of the Federal Facility Agreement and Consent Order (FFACO, 1996; as amended February 2008). CAU 134 is located in Areas 3, 15, and 29 of the Nevada Test Site and consists of the following four Corrective Action Sites (CASs).

- CAS 03-01-03, Aboveground Storage Tank, is located near the location of the U3em (UMBER) Test in Area 3. It consists of one aboveground storage tank (AST) that contains uncontaminated mud. The tank is uncontaminated and has not released compounds that would have contaminated the environment or created a safety hazard.

- CAS 03-01-04, Tank, is located at the Core Handling Complex in Area 3. It consists of one 20,000-gallon aboveground water storage tank. The tank contained potable water and has not released compounds that would have contaminated the environment or created a safety hazard.

- CAS 15-01-05, Aboveground Storage Tank, is located on a steep hillside below the entrance to the old Climax Mine. It consists of one 1,000-gallon aboveground tank and soil that may be impacted by a release from the AST.

- CAS 29-01-01, Hydrocarbon Stain, consists of stained soil under the north end of an active diesel AST at the Shoshone Receiver Site in Area 29. The soil was stained by a release from the AST. The AST is not included in the CAS.

CAU 134 will be closed under the Streamlined Approach for Environmental Restoration process, as dictated by Appendix III of the FFACO. Closure of CAU 134 will be accomplished by completing the following activities:

- The CAS 03-01-04 tank will be closed by taking no further action.

- ASTs from CASs 03-01-03 and 15-01-05 will be dispositioned in accordance with applicable federal, state, and local regulations, and the CAS 03-01-03 site will be closed by taking no further action with implementation of best management practices.

- Soil beneath the CAS 15-01-05 AST and the soil at CAS 29-01-01 will be sampled to identify whether the soil has been contaminated at concentrations greater than the established action levels. If action levels are not exceeded, then no further action is required. It also appears that the CAS 15-01-05 tank is not in its original location. If the original location of the CAS 15-01-05 AST is found, then soil from this location will also be sampled. If the original location is not found, then samples will only be collected at the current tank location.

- If soil at CAS 15-01-05 or 29-01-01 has been contaminated at concentrations greater than final action levels, then additional samples will be collected to identify the extent of contamination and the CAS will be closed in place with implementation of use restrictions. If the impacted area is less than one cubic yard and it is determined that clean closure is feasible based on site conditions, the impacted soil may be excavated and the CAS would then be clean closed. 
SAFER Plan - CAU 134

Section: Executive Summary

Revision: 0

Date: May 2008

THIS PAGE INTENTIONALLY LEFT BLANK 


\subsection{INTRODUCTION}

This Streamlined Approach for Environmental Restoration (SAFER) Plan identifies the activities required for the closure of Corrective Action Unit (CAU) 134, Aboveground Storage Tanks. CAU 134 is currently listed in Appendix III of the Federal Facility Agreement and Consent Order (FFACO) (FFACO, 1996; as amended February 2008) and consists of four Corrective Action Sites (CASs) located in Areas 3, 15, and 29 of the Nevada Test Site (NTS) (Figure 1):

- CAS 03-01-03, Aboveground Storage Tank

- CAS 03-01-04, Tank

- CAS 15-01-05, Aboveground Storage Tank

- CAS 29-01-01, Hydrocarbon Stain

CAS 03-01-03 consists of a mud tank that is located at the intersection of the 3-07 and the 3-12 Roads in Area 3 of the NTS. The tank and its contents are uncontaminated and will be dispositioned in accordance with applicable federal, state, and local regulations. This CAS will be closed by taking no further action.

CAS 03-01-04 consists of a potable water tank that is located at the Core Complex in Area 3 of the NTS. The tank will be closed by taking no further action.

CAS 15-01-05 consists of an aboveground storage tank (AST) and associated impacted soil, if any. This CAS is located on a steep slope near the Climax Mine in Area 15 of the NTS. The AST is empty and will be dispositioned in accordance with applicable federal, state, and local regulations. Soil below the AST will be sampled to identify whether it has been impacted by chemicals at concentrations exceeding the action levels. It appears that the tank is not at its original location. Soil will also be sampled at the original tank location, if it can be found. If soil at either location has been impacted at concentrations that exceed the action levels, then the extent of contamination will be identified and a use restriction (UR) will be implemented. The site may be clean closed if contamination is less than one cubic yard in extent and can be readily excavated. If action levels are not exceeded, then no further action is required.

CAS 29-01-01 consists of soil that has been impacted by a release or operations from an active diesel AST that fuels the generator at the Shoshone Receiver Site in Area 29 of the NTS. Soil below the AST will be sampled to identify whether it has been impacted at concentrations exceeding the action levels. If it is, then the extent of contamination will be identified and a UR will be implemented. The site may be clean closed if contamination is less than one cubic yard in extent, can be readily excavated, and it is determined that clean closure is feasible based upon site conditions. If action levels are not exceeded, then no further action is required.

Based on review of the preliminary assessment information for CAU 134 and recent site inspections, there is sufficient process knowledge to close CAU 134 using the SAFER process.

\subsection{SAFER PROCESS}

CAUs that may be closed using the SAFER process have conceptual corrective actions that are clearly identified. Consequently, corrective action alternatives can be chosen prior to completing a corrective action investigation, given anticipated investigation results. 


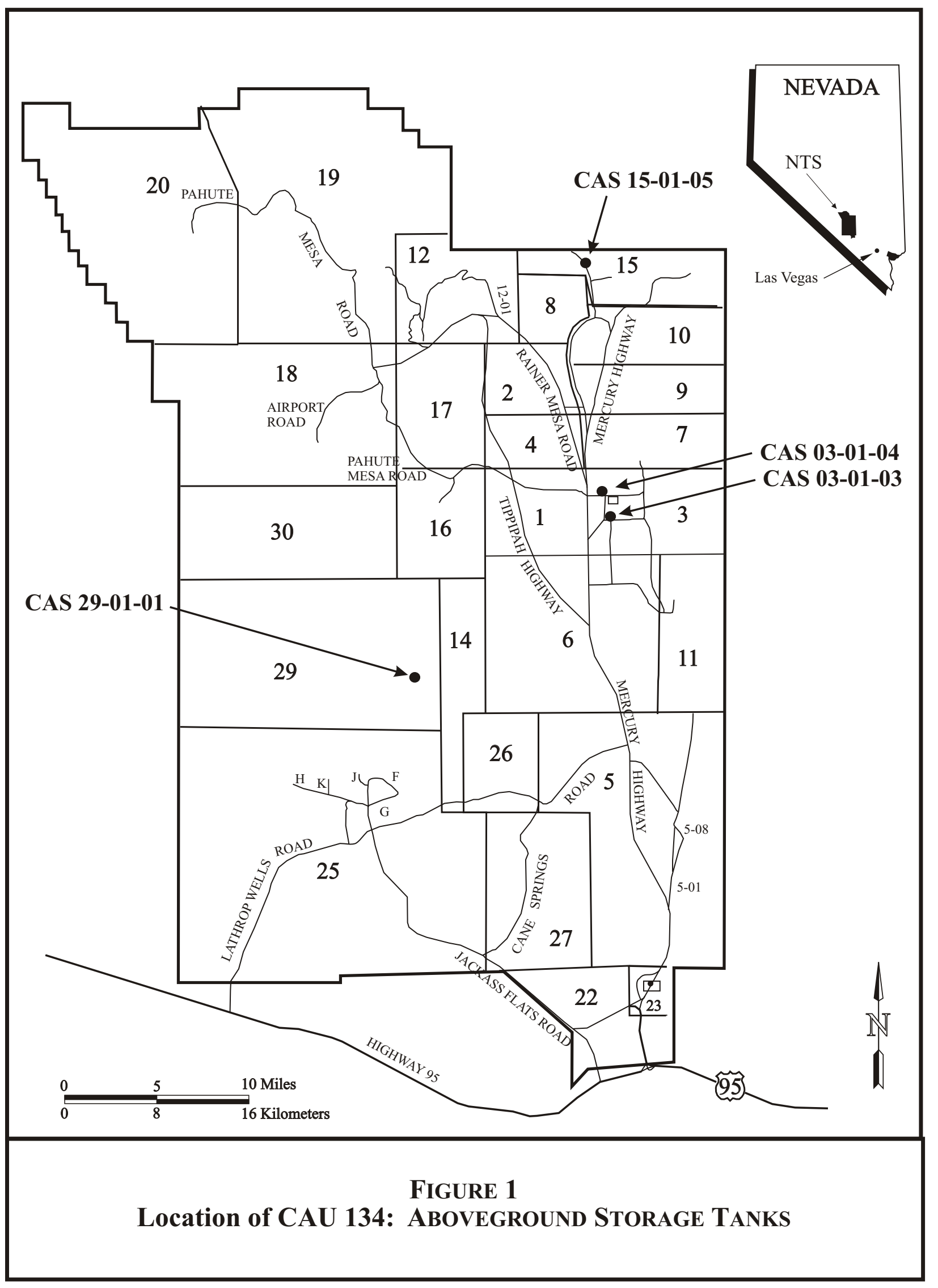


The SAFER process combines elements of the data quality objective (DQO) process and the observational approach to plan and conduct closure activities. The DQOs are used to identify the problem and define the type and quality of data needed to complete the investigation phase of the SAFER process. The purpose of the investigation phase is to verify the adequacy of existing information used to determine the chosen corrective action. The observational approach provides a framework for managing uncertainty during the planning and decision-making phases of the project.

The SAFER process allows for technical decisions to be made based on information gathered during site visits, interviews, meetings, research, and a consensus of opinion by the CAU 134 team members. Any uncertainties are addressed by documented assumptions that are verified by sampling and analysis, data evaluation, onsite observations, and contingency plans, as necessary.

Closure activities may proceed simultaneously with site characterization as sufficient data are gathered to confirm or disprove the assumptions made during selection of the corrective action. If, at any time during the closure process, new information is discovered indicating that closure activities should be revised, closure activities will be reevaluated as appropriate.

Based on a detailed review of historical documentation, there is sufficient process knowledge to close CAU 134 using the SAFER process. The contaminants of concern (COCs) have been determined and are discussed in Section 4.1.

\subsection{Summary of Proposed Corrective ACtions}

Closure of CAU 134 will be accomplished by completing the following activities:

- No further action will be taken at CAS 03-01-04.

- Identify biasing factors dependent on the tank location, such as stained soil or AST openings from which contents may have been released to the soil, to determine where soil samples should be collected at CASs 15-01-05 and 29-01-01.

- Dispose of CAS 03-01-03 and 15-01-05 ASTs or provide for other disposition in accordance with applicable federal, state, and local regulations. While the CAS 15-01-05 tank is being removed, identify any additional biasing factors that may not have been visible before the tank was moved.

- Sample soil at CASs 15-01-05 and 29-01-01 to determine whether action levels have been exceeded.

- Collect step-out samples, where needed, to identify extent of impacted soil requiring a UR.

- Determine whether clean closure is feasible, depending on site conditions. If so, excavate impacted soil and collect cleanup verification soil samples.

- Implement URs, if needed.

The final end state of CAS 03-01-03 will be no further action with implementation of best management practices (BMPs). The final end state of CAS 03-01-04 will be no further action. The final end state of CAS 15-01-05 is expected to be no further action with implementation of BMPs. The final end state of CAS 29-01-01 is uncertain but could be either no further action or closure in place with implementation of a UR. 
The closure strategy outlined in this SAFER Plan (1) provides for the proper disposition of CASs 03-01-03 and 15-01-05 ASTs, and (2) provides for worker notification of hazards, if any, in the form of URs. If concentrations do not exceed action levels, then no further action is required and human health and the environment are unaffected.

\subsection{Hold Points}

During closure activities, certain conditions affecting the project schedule and budget may require decisions to be made prior to continuing work. The CAU 134 project team will anticipate and minimize the necessary hold points by establishing specific alternative actions. If a hold point is reached, other activities not dependent on that hold point (e.g., work at another CAS) may still continue, be performed concurrently, or completed in other than specified time frames. Key activities have been analyzed, and the specific potential hold points include:

- Detection of contaminated soil in much greater volumes than anticipated at CASs 15-01-05 and 29-01-01 such that contamination extends beyond the CAS boundaries. This would particularly be the case if subsurface samples collected from a down-slope location outside of the CAS boundaries contain contamination exceeding action levels.

If at any time during the course of closure activities a hold point is reached, the U.S. Department of Energy, National Nuclear Security Administration Nevada Site Office (NNSA/NSO) will obtain consensus with the Nevada Division of Environmental Protection (NDEP) prior to beginning the next phase of closure activities.

In addition to the above expected hold points, work may be temporarily suspended until satisfactory resolution of any of the following conditions:

- Conditions outside the scope are encountered.

- Radiological screening yields results that require an upgrade in radiological controls to continue work in specific areas.

- Unexpected waste, contamination, or other conditions are encountered.

- Out-of-scope work activities are required due to the detection of COCs not previously identified.

- Unsafe conditions or work practices posing a threat to personnel, equipment, or the environment not originally documented in the Site-Specific Health and Safety Plan (SSHASP) or other safety planning document (e.g., a job hazard analysis [JHA]) are encountered.

- Other administrative or technical issues are encountered that require the preparation of a "Record of Technical Change" to the approved SAFER Plan.

\subsection{SAFER Plan CONTENTS}

This SAFER Plan has been developed to support the closure of CAU 134 as required by the FFACO, DQO (Section 3.0), Project Organization (Appendix A), and Quality Assurance Project Plan (QAPP) (U.S. Department of Energy, National Nuclear Security Administration Nevada Operations Office [NNSA/NV], 2002), and includes the following sections:

- Section 1.0 - Introduction 
- Section 2.0 - Unit Description

- Section 3.0 - Data Quality Objectives

- Section 4.0 - Field Activities and Closure Objectives

- Section 5.0 - Reports and Records Availability

- Section 6.0 - Investigation/Remediation Waste Management

- Section 7.0 - Quality Assurance/Quality Control

- Section 8.0 - References

- Appendix A - Project Organization

- Library Distribution List 
SAFER Plan - CAU 134

Section: Introduction

Revision: 0

Date: May 2008

\section{THIS PAGE INTENTIONALLY LEFT BLANK}




\subsection{UNIT DESCRIPTION}

CAU 134, Aboveground Storage Tanks, is comprised of four CASs located in Areas 3, 15, and 29 of the NTS (Figure 1). CAS 03-01-03, which is located to the west of the U3em borehole in Area 3, consists of one uncontaminated AST. CAS 03-01-04, which is located at the Core Complex in Area 3, consists of one potable-water tank. CAS 15-01-05, which is located on the side of the hill and below the entrance to the old Climax Mine in Area 15, consists of one AST and associated, impacted soil, if any. CAS 29-01-01, which is located beneath the active AST servicing the Shoshone Receiver Site generator, consists of soil that has been impacted with diesel fuel that may have been released from the AST.

\subsection{HiSTORY}

\subsubsection{CAS 03-01-03, Aboveground Storage TANK}

CAS 03-01-03 consists of one AST with approximate dimensions of 24 feet ( $\mathrm{ft}$ ) long by $12 \mathrm{ft}$ diameter. The tank was originally a pressure vessel used elsewhere, at an unknown location. In 1967, it was retrofitted for use at the UMBER (U3em) test, which was conducted by Los Alamos National Laboratory (LANL) (U.S. Department of Energy, Nevada Operations Office [DOE/NV], 2000b; Henderson, 2007). Any hazards associated with gases contained within the tank would have been mitigated during the retrofit (Holmes and Narver, 1967a; 1967b; 1967c). For the UMBER test, the tank was filled with clean (new) drilling mud, with the intent of remotely plugging the U3em (ground zero) borehole after the test. A fire hose was connected to the tank, through which the mud would have been pumped into the borehole. This setup did not work and was never attempted again.

\subsubsection{CAS 03-01-04, TANK}

CAS 03-01-04 consists of one 20,000-gallon (gal) aboveground tank that was used to store potable water for the Area 3 Core Complex.

\subsubsection{CAS 15-01-05, ABoveground STORAGE TANK}

CAS 15-01-05 consists of one AST and soil below the tank that may have been contaminated by a release from the tank. The site was first identified in the Reynolds Electrical and Engineering Company, Inc. (REECo) document, Nevada Test Site Inventory of Inactive and Abandoned Facilities and Waste Sites (REECo, 1991), which identifies sites of potential environmental concern on the NTS. The history of this CAS is uncertain; however, it is present in the vicinity of debris and equipment around the old Climax Mine and was likely used as a part of the mine operations based on its location, age, and condition.

\subsubsection{CAS 29-01-01, HYDROCARBON STAIN}

This CAS consists of diesel-stained rocky soil at the base of an active 2,000-gal diesel AST that is located at the Shoshone Peak Receiver Site. The tank stores fuel for the generator at the Shoshone Receiver Site, which is used for communications at the NTS. This facility, including the associated tank, is expected to remain active as long as radio transmission/receiving capabilities are needed at the NTS. Because the tank is active, it is not a part of this CAS. 
A 1991 report identifying potential Environmental Restoration (ER) sites on the NTS (REECo, 1991) identified that the tank was leaking and that stained soil was present below the release point. An August 27, 1991, memorandum (Haworth, 1991) reports that a site visit was conducted and staining, although present, was only minor. Recent site visits indicate minor staining is present but there is no evidence of recent releases from the tank.

\subsection{Site LOCATION}

\subsubsection{CAS 03-01-03, ABOVEground StORAGE TANK}

CAS 03-01-03 is located to the west of the U3em borehole (i.e., UMBER Test ground zero). To get to the site, take Mercury Highway north to Angle Road. Turn right (northeast) onto Angle Road and proceed approximately 1.3 miles (mi) to the 3-07 Road. Turn right (east) on the 3-07 Road and proceed 0.5 mi to the intersection with the 3-12 Road. Cross the intersection and proceed northeast to the mud tank, which is located approximately $0.1 \mathrm{mi}$ east of the road.

\subsubsection{CAS 03-01-04, TANK}

CAS 03-01-04 is located at the Area 3 Core Complex. To get to the site, take Mercury Highway north to the 3-03 Road. Turn right (east) on the 3-03 Road and proceed 0.4 mi to the Core Complex, which is on the left (north) side of the road. The Core Complex is fenced and the main gate is on the south side of the fenced area. The water tank is in the center of the facility.

\subsubsection{CAS 15-01-05, ABOVEgROUND StORAGE TANK}

CAS 15-01-05 is located down slope of the Climax Mine entrance. To get to the site, take Mercury Highway north to Rainier Mesa Road. Turn left (northwest) on Rainier Mesa Road and proceed to the 2-07 Road. Turn right (east) on the 2-07 Road and proceed to Circle Road. Turn left (north) on Circle Road and proceed to the 10-02 Road. Turn left (north) on the 10-02 Road and proceed to E Road. Turn right (east) on E Road and proceed to the U.S. Environmental Protection Agency (EPA) Farm. Proceed north on D Road from the EPA Farm into the hills. Open a chain gate over the road or walk to the site. The site is visible looking down over the south edge of the road.

\subsubsection{CAS 29-01-01, HYDROCARBON STAIN}

CAS 29-01-01 is located at the Shoshone Receiver Site in Area 29. To get to the site, take Mercury Highway north to Tippipah Highway. Turn left (northwest) on Tippipah Highway and proceed to Mine Mountain Road. Turn left (southwest) on Mine Mountain Road. At approximately $11.4 \mathrm{mi}$, take a right at the fork in the road and proceed $0.6 \mathrm{mi}$ to the Shoshone Receiver Station, Building 29-2901. The diesel tank is to the north of the station.

\subsection{Process Knowledge}

\subsubsection{CAS 03-01-03, ABoveground STORAGE TANK}

CAS 03-01-03 was most recently used to contain uncontaminated drilling mud to be used for plugging the UMBER Test ground zero borehole (U3em). The tank was originally a pressure vessel that was used elsewhere, and any associated hazards would have been mitigated when the tank was retrofitted for use as a mud tank. According to LANL personnel, the contents of the 
tank would not have been impacted by the test and the outside of the tank would have been impacted the same as the surrounding area. The surrounding area is not posted for radiological hazards. A site visit on December 19, 2007, confirmed that there are no radiological postings, that the tank valve is open and the tank is therefore not pressurized, and that radiological field screening levels are no higher at the open valve than in the surrounding area.

\subsubsection{CAS 03-01-04, TANK}

The CAS 03-01-04 tank was used to store potable water for the Area 3 Core Complex. The NTS water supply system does not have any wells in the vicinity of this complex; therefore, water was brought via truck to this location. The tank supplied water for showers, sinks, and other uses in the Core Handling Building, as is indicated in engineering as-builts from when the tank and facility were operational (Holmes and Narver, 1967d; 1967e; 1967f). "POTABLE WATER" is stenciled onto the side of the tank and is still visible, although it is difficult to read because of oxidation on the exterior of the tank (Figure 2).

\subsubsection{CAS 15-01-05, AbOVEground StORAge TANK}

Tanks used during the Climax Mine operating era were typically used to store either water or fuel for mine operations. The tank is located down the hillside from the mine entrance and is not likely at its original location. It appears that the tank either fell and rolled from its original location near Climax Mine entrance, or was dumped at the side of the road and rolled to its present location. The tank is approximately $12 \mathrm{ft}$ long by $4 \mathrm{ft}$ diameter. It is metal, rusty, dented, empty, lying on its side, and is open to the environment. The tank has been radiologically surveyed and confirmed that it is below the free-release limits.

\subsubsection{CAS 29-01-01, HYDROCARBON STAIN}

Based on historic information and known tank contents, the hydrocarbon stain that comprises this CAS is diesel fuel that was spilled or released from the tank. During a 1999 site visit, a metal cap containing a plug of diesel sludge was found lying under the tank's drain valve (Radack, 1999). It appeared that a small volume of diesel may have been released from the tank when the plug was removed and a valve was installed; however, this is speculation and the diesel may have been spilled during other maintenance operations related to the tank.

\subsection{Closure Standards}

The closure standards for each of the following sites is as described below.

\subsubsection{CAS 03-01-03, ABOVEground STORAGE TANK}

No further action is required at this CAS. As a BMP, the tank and its contents will be appropriately dispositioned in accordance with applicable federal, state, and local regulations.

\subsubsection{CAS 03-01-04, TANK}

No further action is required at this CAS. 


\section{FiguRE 2. CAS 03-01-04, TANK}

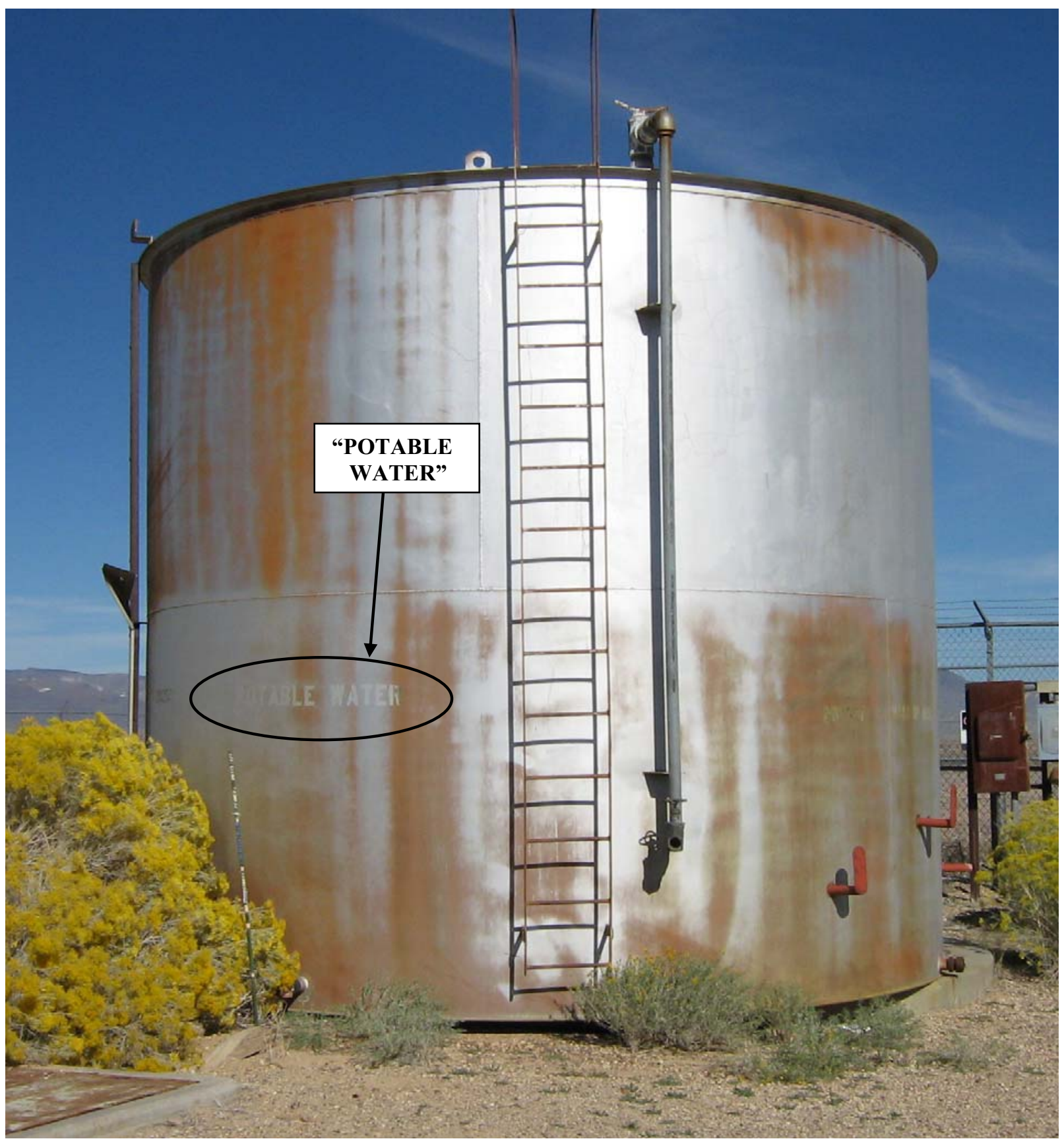




\subsubsection{CAS 15-01-05, Aboveground Storage TANK}

The closure standards for CAS 15-01-05 consist of the following:

- Concentrations of chemicals in soil below the AST and in the original tank location, if found, will be less than the final action levels (FALs) for closure of the site with no further action needed or reduced to less than the FALs for clean closure.

- A UR will be implemented for those areas where remaining chemical concentrations exceed the FALs. Signs will be installed, if required by the "FFACO Use Restriction Posting Guidance for NNSA/NSO and Associated Contractors" (FFACO, 2003).

- As a BMP, the AST will be appropriately dispositioned in accordance with applicable federal, state, and local regulations.

The FALs established for these CASs are identified in Section 3.1.5.3.

\subsubsection{CAS 29-01-01, HYDROCARBON STAIN}

Closure standards for CAS 29-01-01 consist of the following:

- Concentrations of chemicals in soil below the AST will be less than the FALs for closure of the site with no further action needed or reduced to less than the FALs for clean closure.

- A UR will be implemented for those areas where remaining chemical concentrations exceed the FALs. Signs will be installed, if required by the "FFACO Use Restriction Posting Guidance for NNSA/NSO and Associate Contractors" (FFACO, 2003).

The FALs established for these CASs are identified in Section 3.1.5.3. 
SAFER Plan - CAU 134

Section: Unit Description

Revision: 0

Date: May 2008

\section{THIS PAGE INTENTIONALLY LEFT BLANK}




\subsection{DATA QUALITY OBJECTIVES}

The DQO process is a seven-step systematic planning method based on the scientific method that was used to plan data collection and field investigation activities for CAU 134, Aboveground Storage Tanks. The seven steps of the DQO process presented in this report were developed according to the EPA Guidance on Systematic Planning Using the Data Quality Objectives Process (EPA, 2006). DQOs are designed to ensure that the data collected will provide sufficient and reliable information to support the potential closure alternatives for CAU 134. A closure strategy for CAU 134 has been identified; however, additional data are needed to confirm the existence and extent of contamination, if any, and to affirm the closure decision.

During DQO discussions for CAU 134, data needed to resolve problem statements and decision statements were identified. Criteria for data collection and analysis were defined and agreed upon, and the appropriate quality assurance (QA)/quality control (QC) required for particular data collection activities were assigned. The analytical methods and reporting limits prescribed through the DQO process and the data quality indicators (DQIs) for laboratory analysis, such as precision and accuracy requirements, are provided in more detail in Section 7.0 of this SAFER Plan.

\subsection{SUMMARY OF DQO ANALYSIS}

\subsubsection{State The Problem (Step 1)}

Step 1 of the DQO process describes the problem to be studied and develops a conceptual site model (CSM) to gain a sufficient understanding in defining the problem.

The problem statement for CAU 134 is, "Additional information is required to verify existing information; confirm the absence or presence of COCs; identify the extent of contamination, if present; and affirm the closure decision." A COC is defined as any contaminant in the soil that is present at concentrations exceeding its FAL.

\subsubsection{1 $\underline{\text { CSM }}$}

The CSM is used to organize and communicate information about site characteristics. It reflects the best interpretation of available information at any point in time. The CSM is based on historical documentation, personnel interviews, site process knowledge, site walkdowns, photographs, engineering drawings, field screening, and analytical results. The CSM describes the most probable scenario for current conditions at the site and defines the assumptions that are the basis for identifying an appropriate sampling strategy and data collection methods.

The CSM for CAU 134 consists of localized, limited contamination sources (i.e., ASTs) that have released none, all, or a portion of their contents to the surrounding soil. The CSM for each of the CASs is presented in the following paragraphs.

CAS 03-01-03, Aboveground Storage Tank, consists of one 25-ft-long, 12-ft-diameter AST and soil below the AST that may have been impacted by the AST contents. As identified on engineering drawings and by LANL employees, the tank was associated with the UMBER (U3em) test, which was conducted by LANL in 1967 (Henderson, 2007; Holmes and Narver, $1967 \mathrm{a} ; 1967 \mathrm{~b} ; 1967 \mathrm{c}$ ). The tank was originally a pressure vessel used elsewhere (unknown 
location). Any hazards associated with gases contained within the tank would have been mitigated when the tank was retrofitted in 1967, at which time the lining in the tank was removed. The tank was retrofitted and filled with clean (new) drilling mud, with the intent of remotely plugging the U3em (ground zero) borehole after the test. A fire hose was connected to the tank, through which the mud would have been pumped into the borehole. It did not work and was never attempted again.

According to LANL personnel (Henderson, 2007), the contents of the tank would not have been impacted by the test, and the outside of the tank would have been impacted the same as the surrounding area. The surrounding area is not posted for radioactivity. A site visit on December 19, 2007, confirmed that there are no radiological postings, that the tank valve is open and the tank is therefore not pressurized, and that radiological field-screening levels are no higher at the open valve or the tank surface than in the surrounding area. The CSM for this CAS therefore is that of a container that has adequately contained its contents, which is uncontaminated mud. No further investigation or sampling is needed to confirm this CSM. Existing field-screening results are available in the Management and Operations Contractor (M\&OC) files in Mercury, Nevada. This CSM is presented in Figure 3.

CAS 03-01-04, Tank, consists of one 16-ft-diameter, 14 $\frac{1}{2}$-ft-tall potable water tank. As identified on engineering drawings, the tank was used to supply water to the Core Handling Building at the Core Complex in Area 3 (Holmes and Narver, 1967d; 1967e; 1967f). This facility was never connected to the NTS public water system because of the distance to the nearest water supply well; therefore, water was trucked to and stored within this tank. As is indicated on the drawings, the tank stored water that was used for showers, sinks, and other water supply sources within the Core Handling Building. "POTABLE WATER" is stenciled onto the side of the tank (see Figure 2). Process knowledge is adequate to state that there are no COCs associated with this site and no further action is required.

CAS 15-01-05, Aboveground Storage Tank, consists of one old, metal, rusty, dented, empty 1,000-gal AST (approximately $12 \mathrm{ft}$ long by $4 \mathrm{ft}$ diameter) and soil below the AST that may have been impacted by the AST contents. The tank is located in the vicinity of other debris near the Climax Mine, which pre-dates the existence of the NTS. The tank is located on a steep, rocky hillside below the mine entrance. It appears that the tank either fell and rolled from its original location near the mine entrance, or was dumped at the side of the road and rolled to its present location. The tank is currently open and there are no biasing factors to indicate that a release has occurred at this location. Radiological surveys conducted during site visits show that radioactivity is less than the free-release limits.

Historical use of the tank is undocumented, although it appears to pre-date the NTS. For mining operations during this era, similar tanks were typically used to store either water or fuel. If the tank did release its contents to the soil, a slow release would have impacted soil directly below the tank and down to bedrock, after which it would flow downhill over the top of bedrock at the alluvium-bedrock interface. This would not have impacted surface soil except in the immediate vicinity of the tank, with a catastrophic release impacting a larger surface area. 

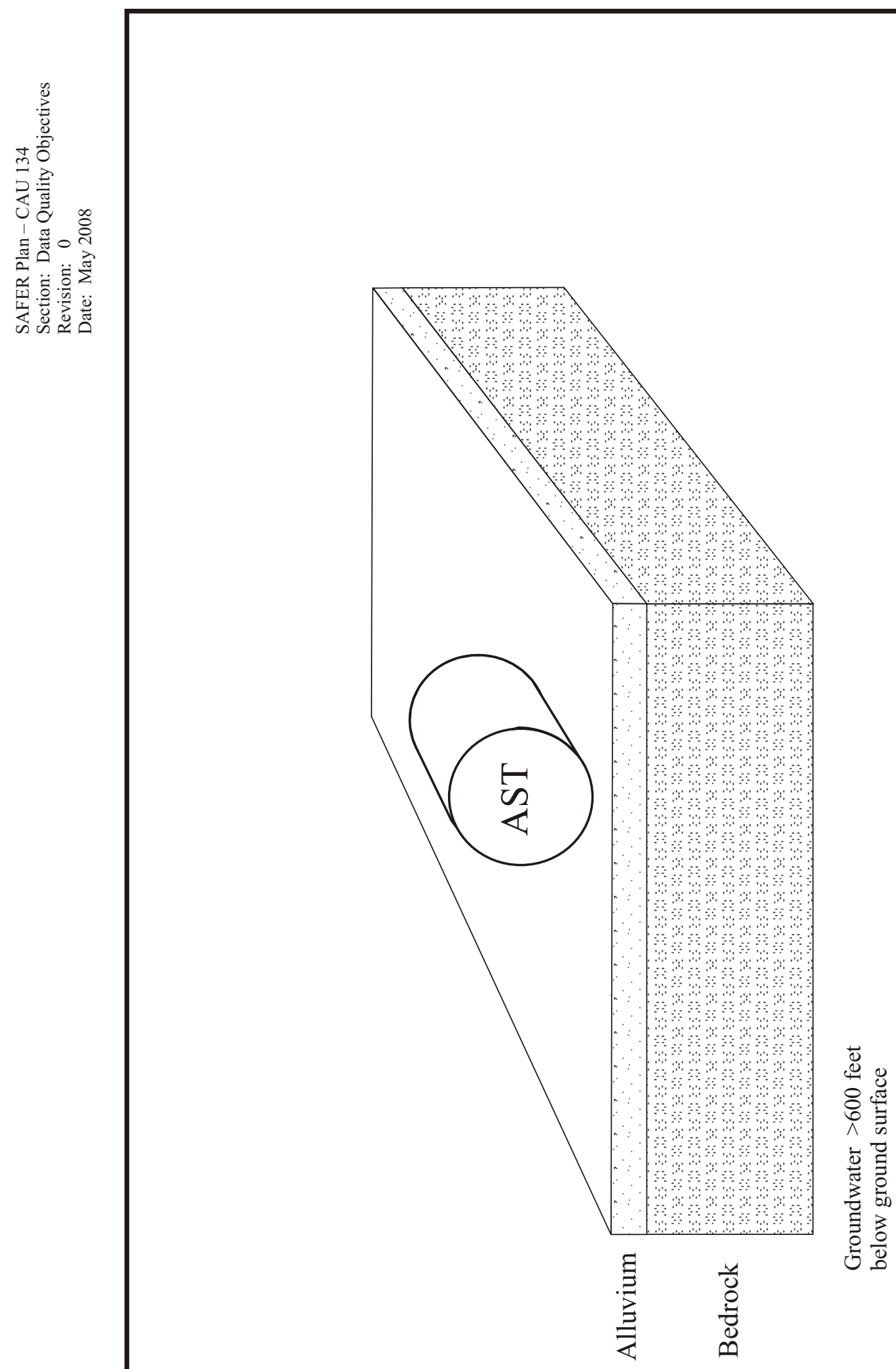

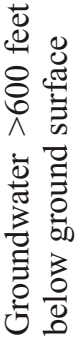

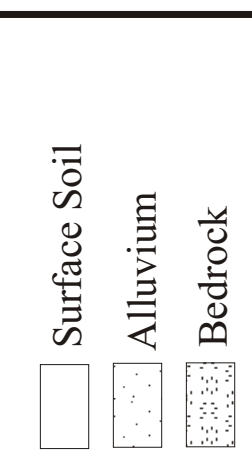

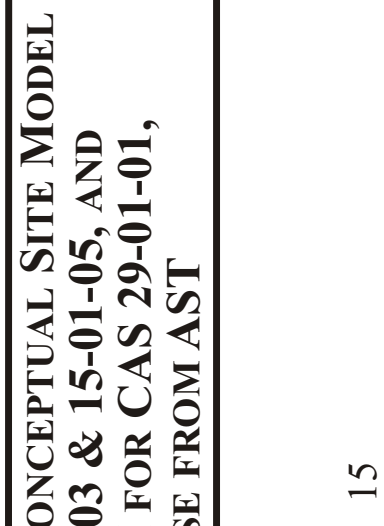

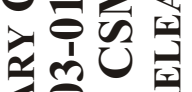
$\sum$ 四

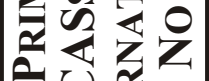
는

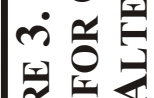
 
The primary driver for contaminant migration would be rain driving the contaminant plume farther down the side of the hill. With annual average rainfall of 6-7 inches (Air Resources Laboratory, Special Operations and Research Division, 2004), migration would be minimal. There is little likelihood that a 1,000-gal release (i.e., the capacity of the tank) would have impacted groundwater, which is at least $600 \mathrm{ft}$ below ground surface (DOE/NV, 2000a), or any drinking water wells, the nearest or which is more than 6 mi away.

The tank likely arrived at its current location empty; therefore, the Primary CSM is that soil below the AST has not been contaminated by the tank contents. The Alternate CSM assumes that the contents of the AST (some or all) consisted of petroleum hydrocarbons, not water, and were released to the soil at its current location. The Primary CSM is presented in Figure 3. The Alternate CSM is presented in Figure 4.

CAS 29-01-01, Hydrocarbon Stain, consists of diesel-contaminated rocky soil at the base of an active 2,000-gal diesel AST. The tank stores fuel for the generator at the Shoshone Receiver Site, which is used for communications at the NTS. This facility, including the associated tank, is expected to remain active as long as radio transmission/receiving capabilities are needed at the NTS. Because the tank is active, it is not a part of this CAS. Overhead power lines and guy lines for the receiver tower are present to the west of the site, and aboveground fuel lines are present between the tank and the adjacent building.

There is no evidence of recent releases from the tank. A 1991 report identifying potential ER sites on the NTS (REECo, 1991) identified that the tank was leaking and that stained soil was present below the release point. An August 27, 1991, memorandum (Haworth, 1991) reports that a site visit was conducted, and staining, although present, was only minor. Recent site visits show that minor staining is still visible. The Primary CSM for this site is that a release from the tank occurred. The Alternate CSM assumes that a release has not occurred. Figure 4 depicts the Primary CSM, and Figure 3 depicts the Alternate CSM for CAS 29-01-01.

Waste that is expected to be generated from CAU 134 consists of the ASTs from CASs 03-01-03 and 15-01-05, disposable sampling equipment, and personal protective equipment. If additional CSM elements that are outside the scope of the CSM are identified during closure activities, the situation will be reviewed and a recommendation will be made regarding to how to proceed. In such cases, the NDEP and the NNSA/NSO will be notified and given the opportunity to comment on, or concur with, the recommendation. 


\section{CAS 15-01-05}

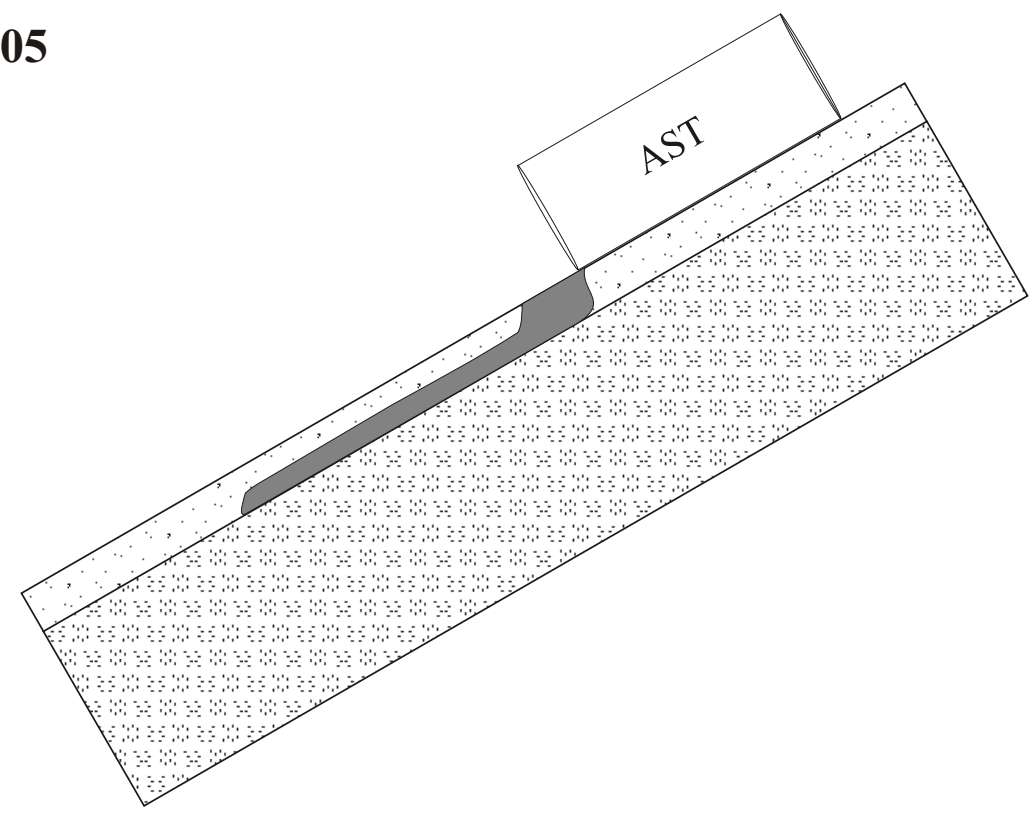

CAS 29-01-01

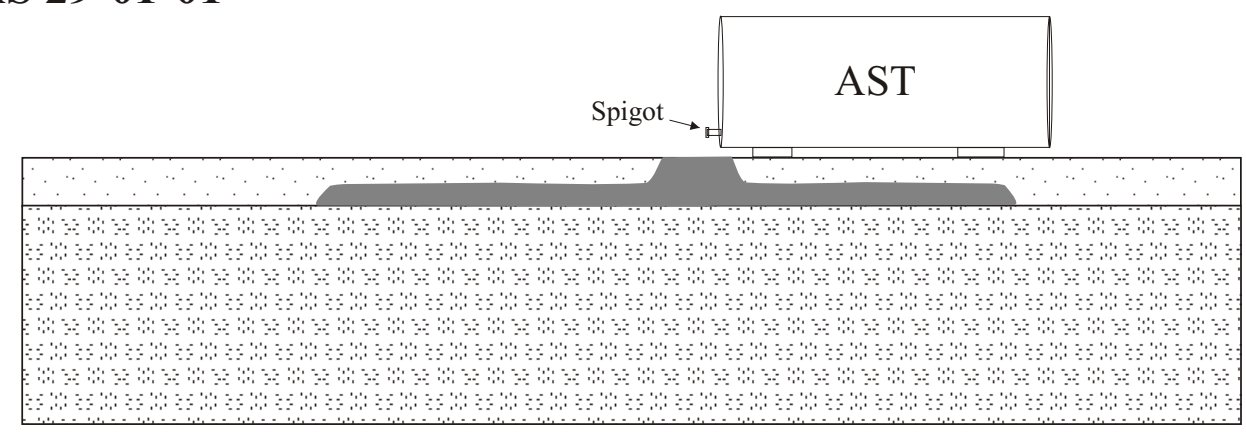

\section{LEGEND}

Contamination

Alluvium

Bedrock

Drawings not to scale

Figure 4. Primary Conceptual Site Model for CAS 29-01-01, AND ALTERNATE CSM FOR CAS 15-01-05, RELEASE FROM AST 


\subsubsection{IDENTIFY THE GOAL OF THE STUDY (STEP 2)}

Step 2 of the DQO process identifies the questions that the study will attempt to resolve and what actions may result. The goal of the study is to answer the following questions satisfactorily. The questions are arranged in the order that they will be addressed.

1. Is soil beneath the ASTs in CASs 15-01-05 and 29-01-01 impacted with contamination that exceeds action levels? The result will be a decision for "no further action" required at the site or that additional evaluation is required to determine if FALs have been exceeded.

2. If the soil is impacted above action levels, what is the extent of the contamination that exceeds action levels? The result will be to evaluate whether the contamination can be excavated or to identify the boundary of the area that should be use-restricted.

3. Has excavation of soil reduced the contamination to concentrations less than the FALs? The result will be to verify that resulting concentrations are at acceptable levels or, if not, to continue excavating until that result has been reached or identify the area that should be use-restricted.

\subsubsection{IDENTIFY INFORMATION INPUTS (STEP 3)}

Step 3 of the DQO process identifies the information available, the information needed, the sources of information, and sampling and analysis methods that can meet the data requirements. Table 1 presents available information, information that is needed, and proposed methods to obtain the information that is needed to meet the closure goal.

\subsubsection{Information Needs}

To confirm the CSM and determine the nature and extent of contamination, data must be collected and analyzed using the following criteria:

- Data will be collected from locations most likely to contain contamination (judgmental sampling approach) at CASs 15-01-05 and 29-01-01.

- The analytical suite selected will be adequate to detect contaminants present in the samples.

- Where data show that contamination is present at concentrations greater than the FALs, data will be collected to identify the extent of contamination.

- If contaminated soil is excavated, cleanup verification samples will be collected to verify that remaining concentrations are less than the FALs.

\subsubsection{Sources of Information}

Information needed to satisfy the decisions will be generated by collecting soil samples. 


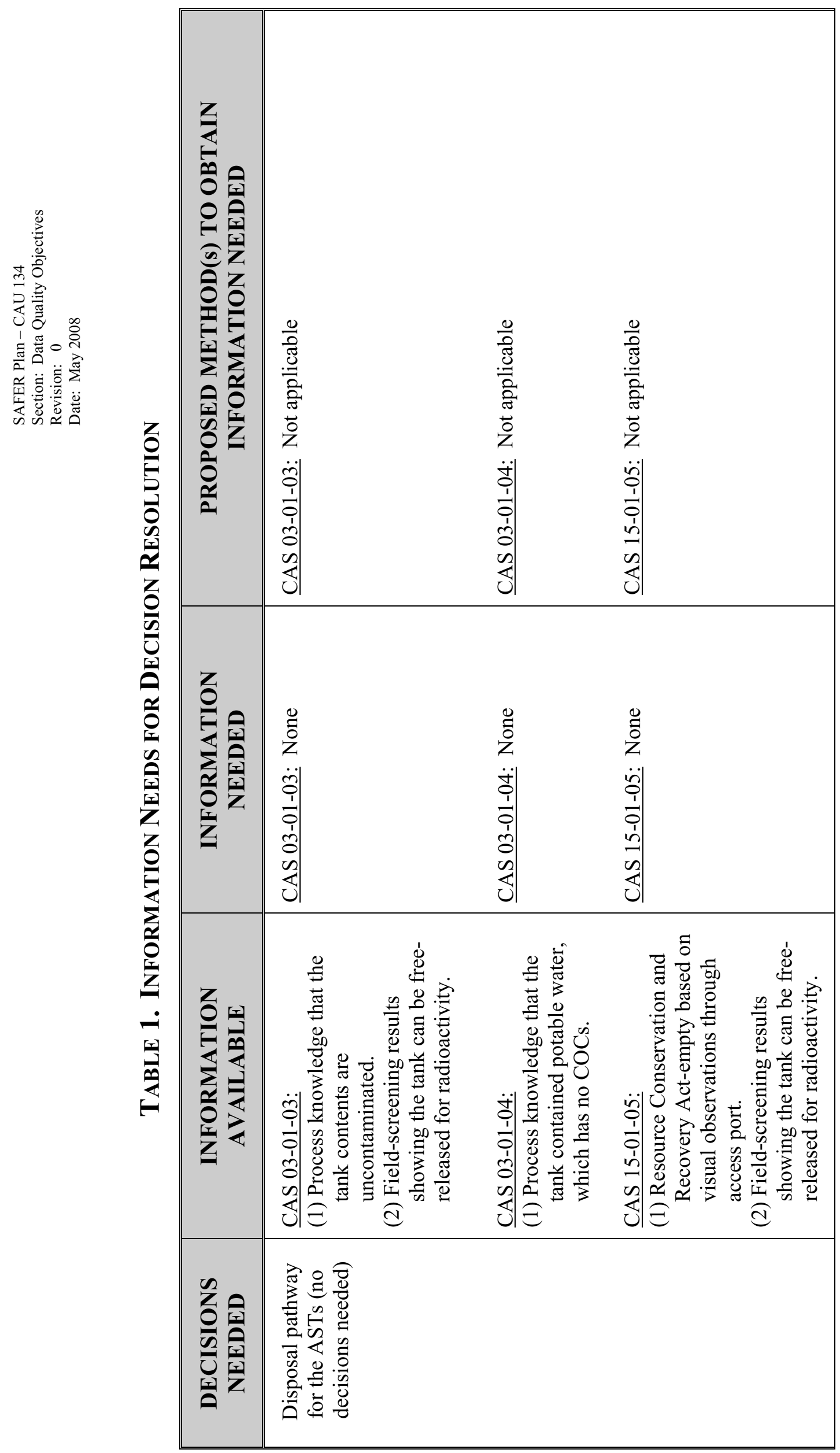




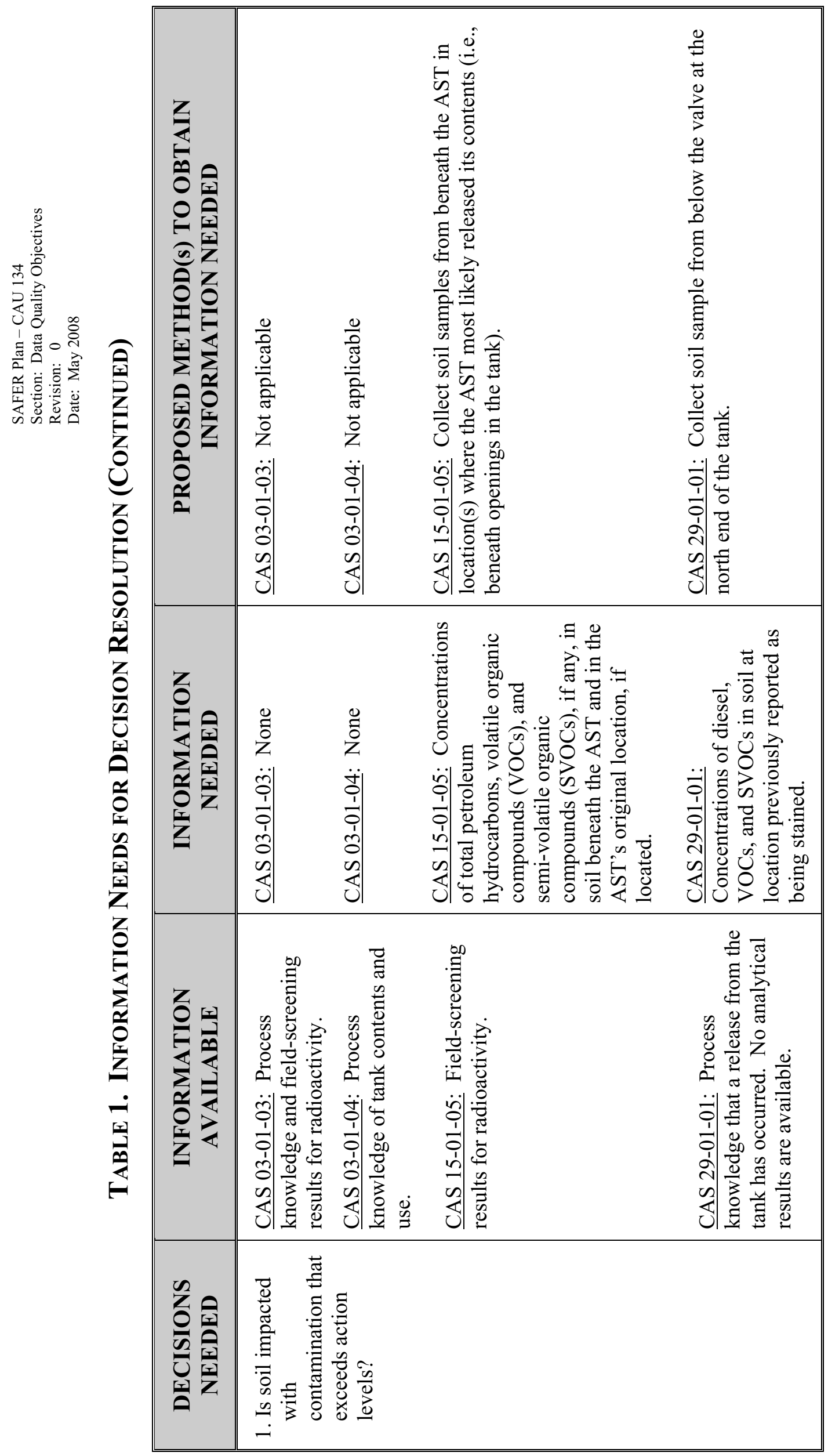




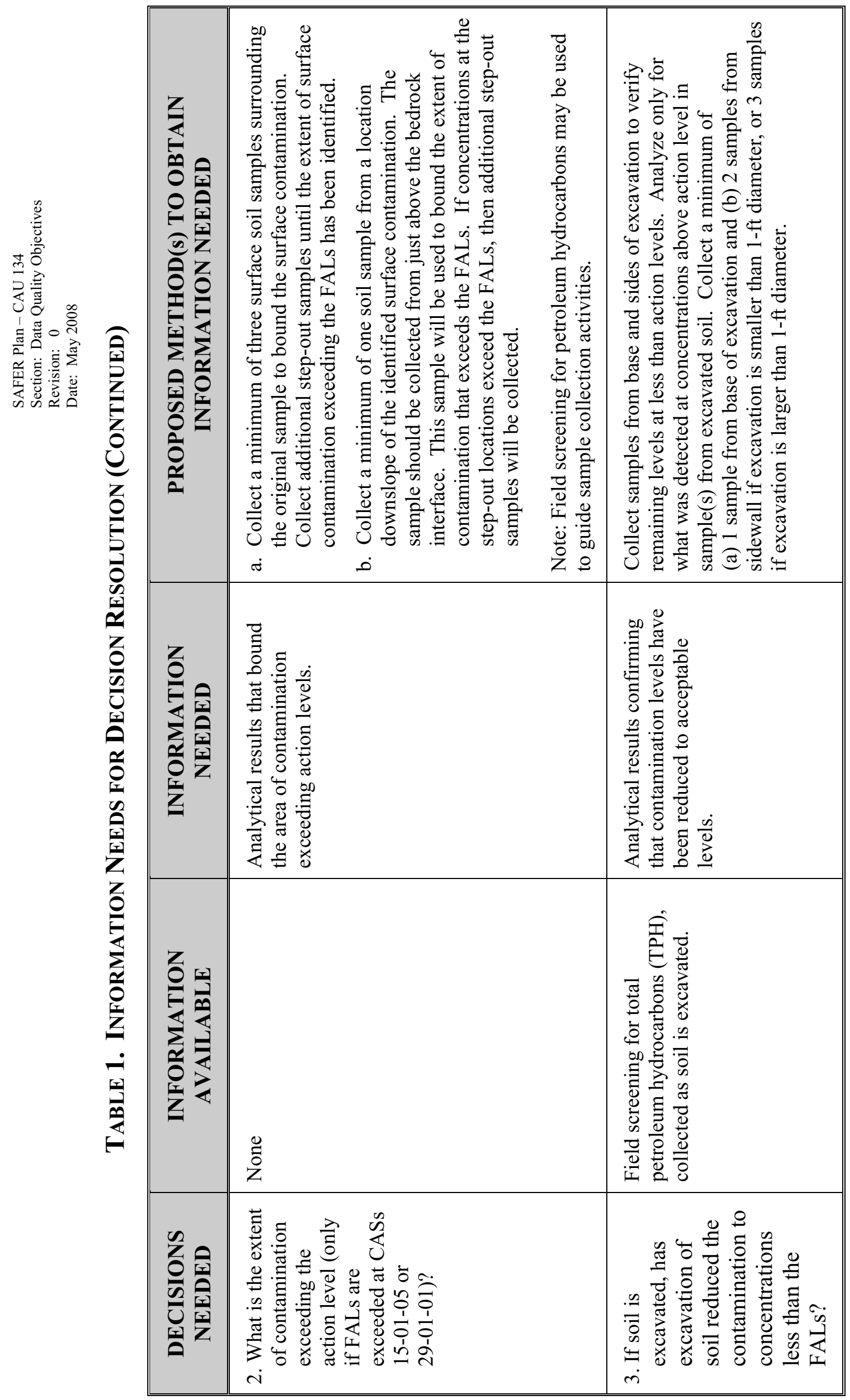




\section{Qualitative Data}

Qualitative data identify or describe the characteristics or components of the site. The QA/QC requirements are the least rigorous on data collection methods and measurement systems for qualitative data. The intended use of the data is for information purposes, to refine conceptual models, and to guide investigations rather than resolve primary decisions. This measurement of quality is typically assigned to historical information and data where QA/QC may be highly variable or not known. Professional judgment is often used to generate qualitative data.

Visual observations will be made to identify the presence of biasing factors such as the location of openings within the ASTs.

\section{Semi-quantitative Data}

Semi-quantitative data indirectly measure the quantity or amount of a characteristic or component. Inferences are drawn about the quantity or amount of a characteristic or component because a correlation has been shown to exist between the indirect measurement and the results from a quantitative measurement. The QA/QC requirements on semi-quantitative collection and measurement systems are high but may not be as rigorous as for quantitative data. Semi-quantitative data contribute to decision making but are not used alone to resolve primary decisions. Field-screening data are generally considered semi-quantitative. The data are often used to guide investigations toward quantitative data collection.

If total petroleum hydrocarbons (TPH) are present at concentrations greater than the action level at CAS 15-01-05 or CAS 29-01-01, then TPH field-screening may be used to identify the extent of contamination greater than the action level. These field-screening techniques will provide semi-quantitative data that can be used to guide sample collection (e.g., obtain locations for biased sample collection) and waste management activities.

\section{Quantitative Data}

Quantitative data measure the quantity or amount of a characteristic or component. These data require the highest level of QA/QC in collection and measurement systems because the intended use of the data is to resolve primary decisions and/or to verify that closure standards have been met. Laboratory analytical data are generally considered quantitative.

A judgmental (biased) sampling approach will be used to collect samples from beneath the ASTs at CASs 15-01-05 and 29-01-01. Biasing factors consist of soil that is stained, located below AST openings, and/or located where staining has been noted.

Samples collected from CAS 15-01-05 will be analyzed for TPH. Samples from CAS 29-01-01 will be analyzed for diesel-range petroleum hydrocarbons. If results show that samples have been impacted at concentrations greater than the TPH action level, then additional samples will be collected to identify whether volatile organic compounds (VOCs) and semi-volatile organic compounds (SVOCs) contained in diesel fuel are greater than action levels (i.e., the FALs). If the FALs are exceeded, then additional samples will be collected to identify the extent of contamination.

Clean closure is not anticipated based on the shallow bedrock at both locations and the presence of the active tank at CAS 29-01-01; however, clean closure may be possible if extent of 
contamination is minimal. If contaminated soil is excavated, then additional samples will be collected and analyzed for those compounds that exceeded the FALs.

Samples will be submitted to analytical laboratories meeting the quality criteria stipulated in the Industrial Sites QAPP (NNSA/NV, 2002). A minimum of 10 percent of the data used to support DQO decisions will be validated. Sample collection and handling activities will follow standard procedures.

\subsubsection{DEFINE THE BOUNDARIES OF THE STUdy (STEP 4)}

Step 4 of the DQO process defines the target population of interest, specifies the spatial boundaries and time constraints of that population pertinent for decision making, and determines practical constraints on data collection.

\subsubsection{Population of Interest}

The population of interest to resolve the decisions consists of the ASTs at CASs 03-01-03 and 15-01-05 and of soil containing petroleum hydrocarbons greater than the action level for CASs 15-01-05 and 29-01-01.

\subsubsection{Spatial Boundaries}

CAS boundaries and proposed sample locations are described below. The spatial boundaries include the following:

- CAS 03-01-03 consists of the AST and its contents. The CAS boundary is considered to be the AST perimeter plus $5 \mathrm{ft}$ (Figure 5).

- CAS 15-01-05 consists of the AST and soil that has been impacted by a release from the tank at its current location and, if found, at its original location. The CAS boundary is considered to be the AST perimeter plus $10 \mathrm{ft}$ uphill and laterally, and $30 \mathrm{ft}$ downhill (Figure 6). If a subsurface sample is collected, it may be collected at a downhill location outside of the CAS boundary. This may be needed because of the extreme slope at this CAS and the inability to safely excavate at the tank's current location.

- CAS 29-01-01 consists of soil that has been impacted by a release from the associated diesel tank. The CAS boundary is considered to be the AST perimeter plus $5 \mathrm{ft}$ on its south end, $20 \mathrm{ft}$ laterally, and $30 \mathrm{ft}$ on its north end, where the release was reported to have occurred (Figure 7).

\subsubsection{Time Constraints}

The study data should be collected considering the length of time that will be required to complete the closure process and the Closure Report (CR), as allowed for by the SAFER process under the FFACO (FFACO, 1996; as amended February 2008). Data will be collected at times that meet the security and safety constraints of the NTS and at times when weather conditions allow adequate site access and safe working conditions. Time constraints that may affect the schedule of this project include the following:

- Approval of SAFER Plan and DQOs

- Activities that restrict access to CAS 15-01-05, which is beyond a barricaded gate requiring approval to proceed 


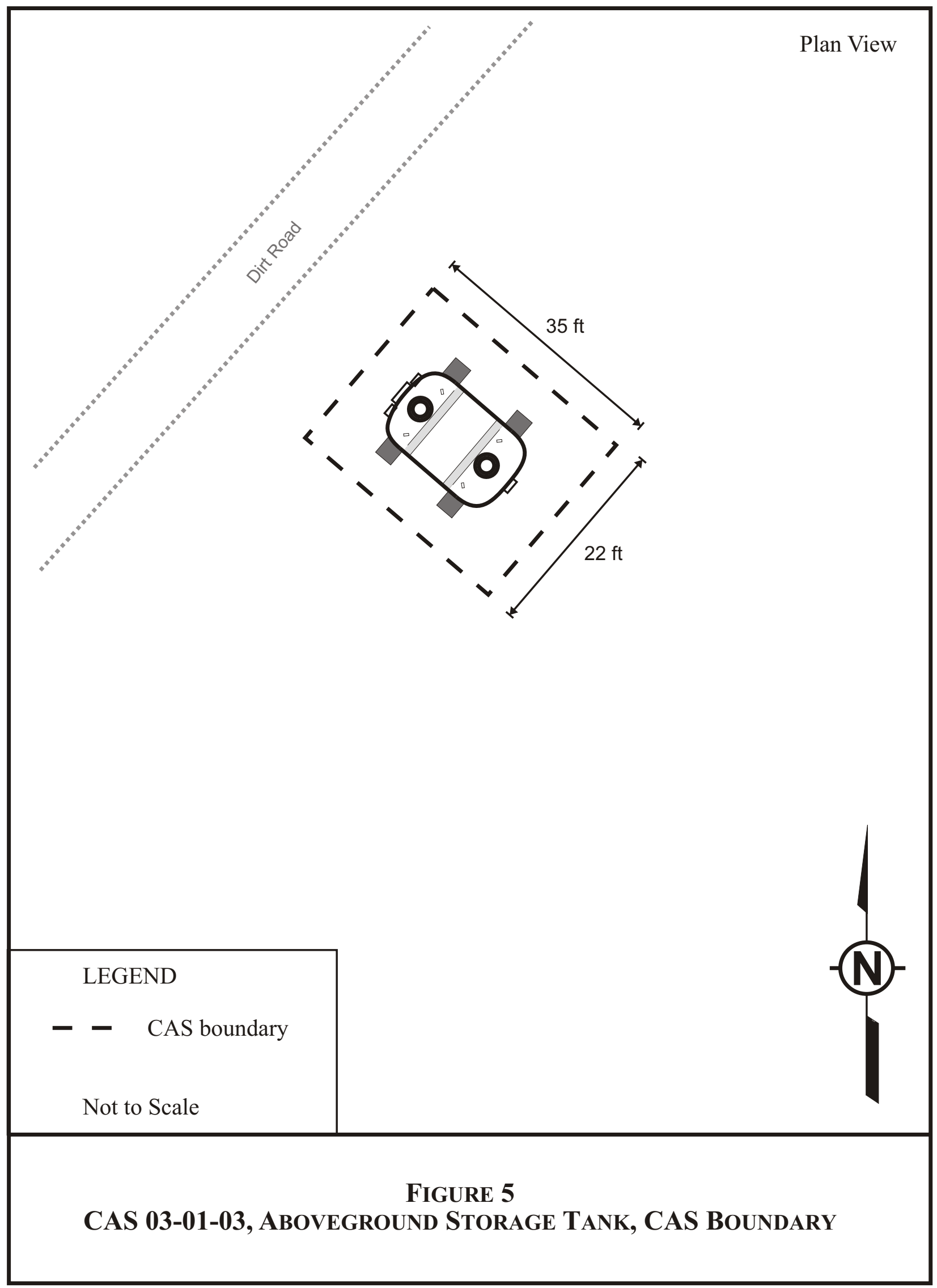




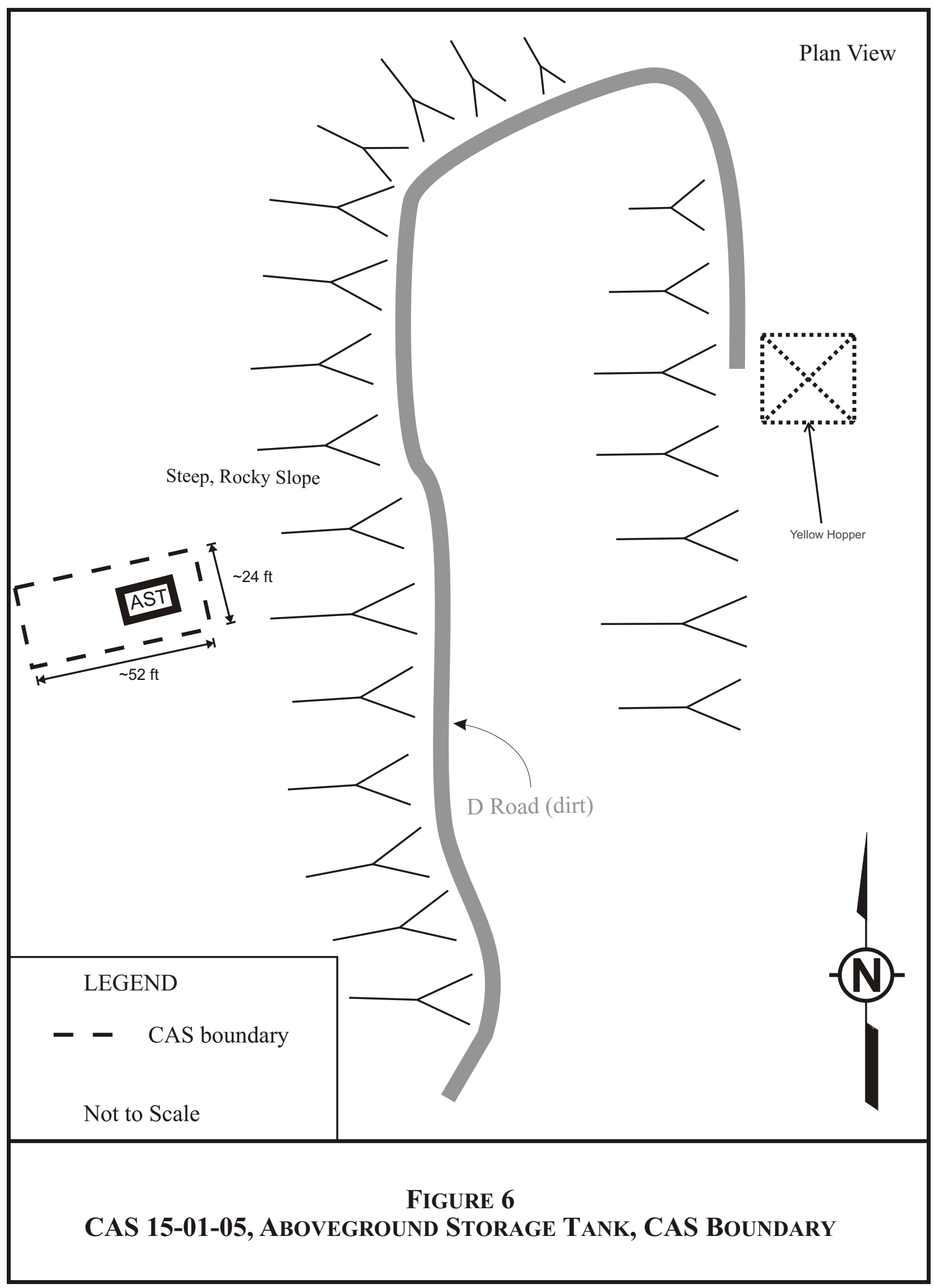




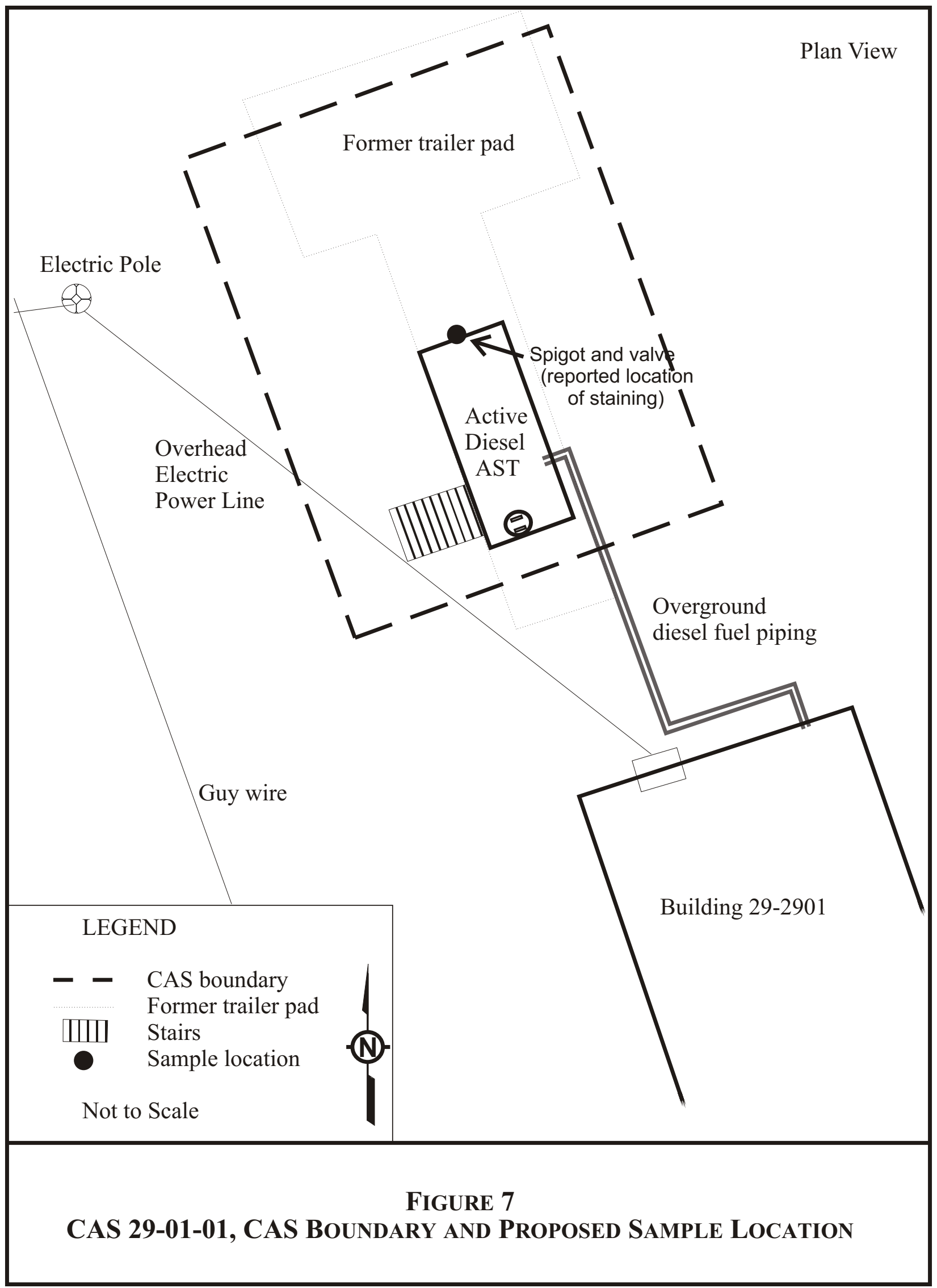


Closure activities are currently scheduled to begin in fiscal year (FY) 2009.

\subsubsection{Practical Constraints}

Other constraints that may affect the ability to collect data include the following:

- Equipment access and availability at NTS

- Road condition for CAS 15-01-05, which is a primitive, unmaintained road in poor condition

- Road condition for CAS 29-01-01, which is not well maintained

- Adverse weather conditions (e.g., snow and ice in the winter months, especially at the sites in Areas 15 and 29)

- Acceptance of waste disposal pathways

- Other unsafe working conditions

\subsubsection{DeVelop the AnAlytic ApProach (STEP 5)}

Step 5 of the DQO process develops a decision rule statement ("If..., then...") that defines the conditions under which possible alternative actions will be chosen. In this step, the statistical parameters that characterize the population of interest are specified, the action levels are specified, and the measurement and analysis limits capable of detecting action levels are confirmed.

\subsubsection{Population Parameters}

Each sample result within the population of interest defined in Step 4 will be compared to the action levels to determine the appropriate resolution to the decisions.

\subsubsection{Decision Rules}

The decision rules are as follows.

\section{Decision I}

- If concentrations in soil samples collected from CASs 15-01-05 or 29-01-01 are less than the preliminary action level (PAL), then no further action is required. Closure is complete at this CAS.

- If concentrations in soil samples collected from CASs 15-01-05 or 29-01-01 are greater than the PAL, then the appropriate FALs will be determined above which a closure action is required. Additional samples will be collected, as required. If concentrations in the soil exceed the FALs, then proceed to Decision II for this CAS.

\section{Decision II}

- If soil samples collected from CAS 15-01-05 or 29-01-01 show that concentrations exceed the FAL, then a minimum of three step-out surface soil samples will be collected to bound the area with concentrations greater than the FAL. Additional step-out samples will be collected until the lateral surface area of contamination has been bounded. In addition, a minimum of one sample will be collected from just above the bedrock interface, in the bedrock down slope direction, to bound contamination that has reached the bedrock interface 
and migrated down slope. Additional samples will be collected as needed to bound contamination that has migrated along the alluvium-bedrock interface.

\section{Decision III}

- If the extent of contamination is minimal and can be remediated by excavation, then contaminated soil will be excavated and verification samples will be collected. If verification sample results show that chemical concentrations are less than the FALs, then closure is complete. A minimum of one sample will be collected from the base of the excavation. A minimum of two samples will be collected from sidewalls of excavations $1 \mathrm{ft}$ or less in diameter, and a minimum of three samples will be collected from the sidewalls of excavations larger than $1 \mathrm{ft}$ in diameter to confirm that closure is complete. Samples will only be analyzed for those contaminants that exceeded the action level and triggered the requirement to excavate soil. Ability to excavate may not be possible because of the shallow depth to bedrock and/or unsafe conditions caused by sloping terrain.

- A UR will be implemented for remaining area(s) of contamination that exceed the action level(s).

\subsubsection{Action Levels}

The following action levels have been established for CAU 134:

- TPH: The PAL will be 100 milligrams per kilogram $(\mathrm{mg} / \mathrm{kg})$, as is established in the Nevada Administrative Code (NAC), Section 445A.2272, "Contamination of soil: Establishment of action levels" (NAC, 2006).

- VOCs and SVOCs: FALs will be based on the concentration of individual chemical components of diesel and are defined as the EPA Region 9 risk-based preliminary remediation goals (PRGs) for chemical constituents in industrial soils (EPA, 2004). Table 2 provides the list of volatile and semi-volatile compounds with the associated FALs.

\subsubsection{Measurement and Analysis Sensitivity}

Samples may be field-screened to help identify the area of contamination; however, final decisions will be made based on samples that have been submitted for laboratory analysis. The measurement and analysis methods listed in the Industrial Sites QAPP (NNSA/NV, 2002) are capable of measuring analyte concentrations at or below the corresponding action levels for each constituent. Samples will be analyzed using the following analytical methods:

- $\quad$ TPH samples will be analyzed using EPA Method 8015B for TPH (EPA, 1996).

- $\quad$ VOC samples will be analyzed using EPA Method 8260B (EPA, 1996).

- $\quad$ SVOC samples will be analyzed using EPA Method 8270C (EPA, 1996).

\subsubsection{Specify Performance OR ACCePtance Criteria (Step 6)}

Step 6 of the DQO process specifies performance criteria for the decision rules. Setting tolerable limits on decision errors requires the planning team to weigh the relative effects of threats to human health and the environment, expenditure of resources, and the consequences of an 


\section{Table 2. Chemical Components of Diesel ANd Associated FALs}

\begin{tabular}{|c|c||}
\hline Chemical Compound & $\begin{array}{c}\text { FAL } \\
\text { (mg/kg) }\end{array}$ \\
\hline 1,3,5-Trimethylbenzene & 70 \\
\hline 2-Methylnaphthalene ${ }^{1}$ & 190 \\
\hline Anthracene & 100,000 \\
\hline Benz(a)anthracene & 2.1 \\
\hline Benzene & 1.4 \\
\hline Benzo(a)pyrene & 0.2 \\
\hline Benzo(b)fluoranthene & 21 \\
\hline Benzo(g,h,i)perylene & 29,000 \\
\hline Benzo(k)fluoranthene & 21 \\
\hline Chrysene & 210 \\
\hline Ethylbenzene & 400 \\
\hline Fluoranthene & 22,000 \\
\hline Fluorene & 26,000 \\
\hline Naphthalene & 190 \\
\hline n-Butylbenzene & 240 \\
\hline n-Propylbenzene & 240 \\
\hline Phenanthrene & 100,000 \\
\hline Pyrene & 29,000 \\
\hline Toluene & 520 \\
\hline Xylenes ${ }^{2}$ & 420 \\
\hline
\end{tabular}

\footnotetext{
${ }^{1}$ Uses PRG for napthalene

${ }^{2}$ Total of $\mathrm{m}-$, o-, and $\mathrm{p}$-xylenes

FAL - final action level

$\mathrm{mg} / \mathrm{kg}$ - milligrams per kilogram
}

incorrect decision. This section provides an assessment of the possible outcomes of DQO decisions and the impact of those outcomes if the decisions are in error.

CAU 134 will be sampled using the judgmental sampling approach. The EPA DQO guidelines state that if a judgmental sampling approach is used, quantitative statements about data quality will be limited to measurement error (EPA, 2006). Measurement error is influenced by imperfections in the measurement and analysis system. Random and systematic measurement errors are introduced in the measurement process during physical sample collection, sample 
handling, sample preparation, sample analysis, and data reduction. If measurement errors are not controlled, they may lead to errors in making the DQO decisions.

In general, confidence in DQO decisions based on judgmental sampling results will be established qualitatively by:

- Developing CSMs

- Testing the validity of the CSMs based on investigation results

- Evaluating the quality of the data based on DQI parameters

\subsubsection{Decision Errors}

There is one CAU 134 baseline condition (i.e., null hypothesis) and an associated alternative condition for CAU 134, CASs 15-01-05 and 29-01-01. CAS 03-01-03 has no potential alternative condition because available information is adequate and supports the baseline condition. The baseline condition at CASs 03-01-03, 15-01-05, and 29-01-01 is that soil below the AST is not impacted at concentrations greater than the action level. The alternative condition at CASs 15-01-05 and 29-01-01 is that the soil has been impacted at concentrations above the action level by a release from the tank.

\subsection{False Rejection (False Positive) Decision Error}

This error would mean deciding that the baseline condition is false when, in fact, it is true. This error means deciding that the soil beneath the AST is contaminated at concentrations greater than the action level when it is not. The consequence of this decision is increased cost both for the closure effort and post-closure requirements that should not be needed. False positive errors are typically attributed to laboratory and/or sampling errors that could cause cross contamination. To control against cross contamination, disposable sampling equipment will be used and/or decontamination of sampling equipment will be conducted according to established and approved procedures, and only clean sample containers will be used.

\subsection{False Acceptance (False Negative) Decision Error}

This error would mean deciding that the baseline condition is true when, in fact, it is false. This error means deciding that the soil below the CAS 15-01-05 or CAS 29-01-01 AST (and/or at the original AST location at CAS 15-01-05) is not contaminated when, in fact, it is contaminated above action levels. The potential consequence is an increased risk to human health and the environment. This error will be controlled by meeting these criteria:

- Having a high degree of confidence that the selected sample locations will identify contamination if it is present. To satisfy this criterion, samples will be collected from below tank openings, which are the most likely locations for a release to have occurred. At CAS 29-01-01, a sample will be collected from where the staining has been observed.

- Having a high degree of confidence that the analyses conducted will be sufficient to detect any contamination present in the samples. To satisfy this criterion, the DQI of sensitivity will be assessed for all analytical results to ensure that all sample analyses had detection limits that were less than or equal to the corresponding action level.

- Having a high degree of confidence that the data set is of sufficient quality. To satisfy this criterion, the data will be assessed against the DQIs of precision, accuracy, comparability, 
and completeness, and the appropriate QC samples will be collected as defined in the Industrial Sites QAPP (NNSA/NV, 2002).

\subsubsection{Develop the Plan for ObTaining Data (Step 7)}

Step 7 of the DQO process provides the general approach for obtaining the information necessary to resolve the decisions. A judgmental sampling scheme will be implemented to select sample locations and evaluate analytical results for CASs 15-01-05 and 29-01-01. EPA's DQO guidelines state that a judgmental sampling approach can be used when there is sufficient information on the contamination sources and history to develop a valid CSM and to select specific sampling locations (EPA, 2006). This design is used to confirm the existence of contamination at specific locations and provide information about specific areas of the site. Sample locations for judgmental sampling will be determined based on process knowledge and visual observations.

For CAS 15-01-05, a minimum of one soil sample will be collected from below the AST, from the location(s) most likely to be impacted by a release from the tank. The Climax Mine area will also be checked for visual evidence of the original location of the AST. If the original location of the AST is found, then a minimum of one soil sample will be collected from that location. Samples will be collected from locations where there is visual evidence of a release, such as stained soil. In absence of visual evidence of a release, samples will be collected from below the tank opening that is lowest and most likely to have released fluid. This could be from below an open pipe or from below a rusted-through portion of the tank wall. Site visits have shown no indication of stained soil; however, the area will be evaluated again after the tank has been moved from its current location.

Samples collected from CAS 15-01-05 will be analyzed for TPH (gas-diesel-oil range) using EPA method 8015B (EPA, 1996). If TPH concentrations are less than the $100 \mathrm{mg} / \mathrm{kg}$ PAL, then no further action is needed. If TPH concentrations exceed $100 \mathrm{mg} / \mathrm{kg}$, then samples will be collected and analyzed for VOCs and SVOCs. Results will be compared against the FALs. If concentrations are less than FALs, then no further action is needed.

For CAS 29-01-01, a minimum of one soil sample will be collected from below the spigot at the north end of the AST, which is where staining has been observed. Samples will be analyzed for TPH (diesel-range) using EPA method 8015B (EPA, 1996). If TPH concentrations are less than the $100 \mathrm{mg} / \mathrm{kg}$ PAL, then no further action is needed. If TPH concentrations exceed $100 \mathrm{mg} / \mathrm{kg}$, then samples will be collected and analyzed for VOCs and SVOCs. Results will be compared against the FALs. If concentrations are less than FALs, then no further action is needed.

At either site, if contamination is present at concentrations greater than the FAL, then samples will be collected from surface and subsurface soil to bound the extent of contamination. Samples will only be analyzed for those VOC and/or SVOC compounds that exceeded the FAL. A minimum of three samples will be collected from surface soil (i.e., $0-6$ inches below ground surface) to bound the extent of surface contamination. A minimum of one soil sample will be collected from soil located just above the soil-bedrock interface, at a location that is down slope of the surface contamination. Because of limited access and steeply sloped bedrock at these sites, the subsurface samples may be collected from some distance outside of the CAS 
boundaries. The intent is to confirm that the contamination has not migrated to surface drainages (e.g., dry washes or arroyos).

If contamination is found, the area of contamination greater than the FALs will be closed in place with implementation of a UR. Although clean closure is not planned because of the steep slopes, shallow bedrock, and remote location of these sites, this option may be taken if the extent of contamination is shown to be minimal and able to be excavated safely. To verify clean closure of the site, samples will be collected from the base and sides of the excavation to verify remaining levels are less than action levels. A minimum of (a) 1 sample from the base of the excavation and (b) 2 samples from the sidewall if the excavation is smaller than 1-ft diameter, or 3 samples if the excavation is larger than 1-ft diameter will be collected. Samples will only be analyzed for those compounds that exceeded the FALs.

For CAS 03-01-03, process knowledge and field screening show that there has been no release of regulated substances from the tank; therefore, no soil samples will be collected. CAS 03-01-03 will be closed with no further action. As a BMP, the CAS 03-01-03 and 15-01-05 ASTs will be disposed of or otherwise dispositioned in accordance with applicable federal and state regulations.

The CAS 03-01-04 tank was used to store potable water; therefore, the tank and releases from this tank are not an environmental concern.

A flowchart of the closure decision pathway for CAS 15-01-05 is presented in Figure 8.

\subsection{RESUlTS OF THE DQO ANALYSIS}

\subsubsection{ACTION LeVEL DETERMINATION AND BaSIS}

The following action levels have been established for CAU 134:

- TPH: The PAL will be $100 \mathrm{mg} / \mathrm{kg}$, in accordance with Section 445A.2272 of the NAC (NAC, 1996).

- VOCs and SVOCs: FALs will be the PRGs for chemical constituents in industrial soil (EPA, 2004) for the individual chemical components of diesel, which are presented in Table 2.

If results show that chemical concentrations in the soil exceed the FALs, then a UR will be implemented for the site. 


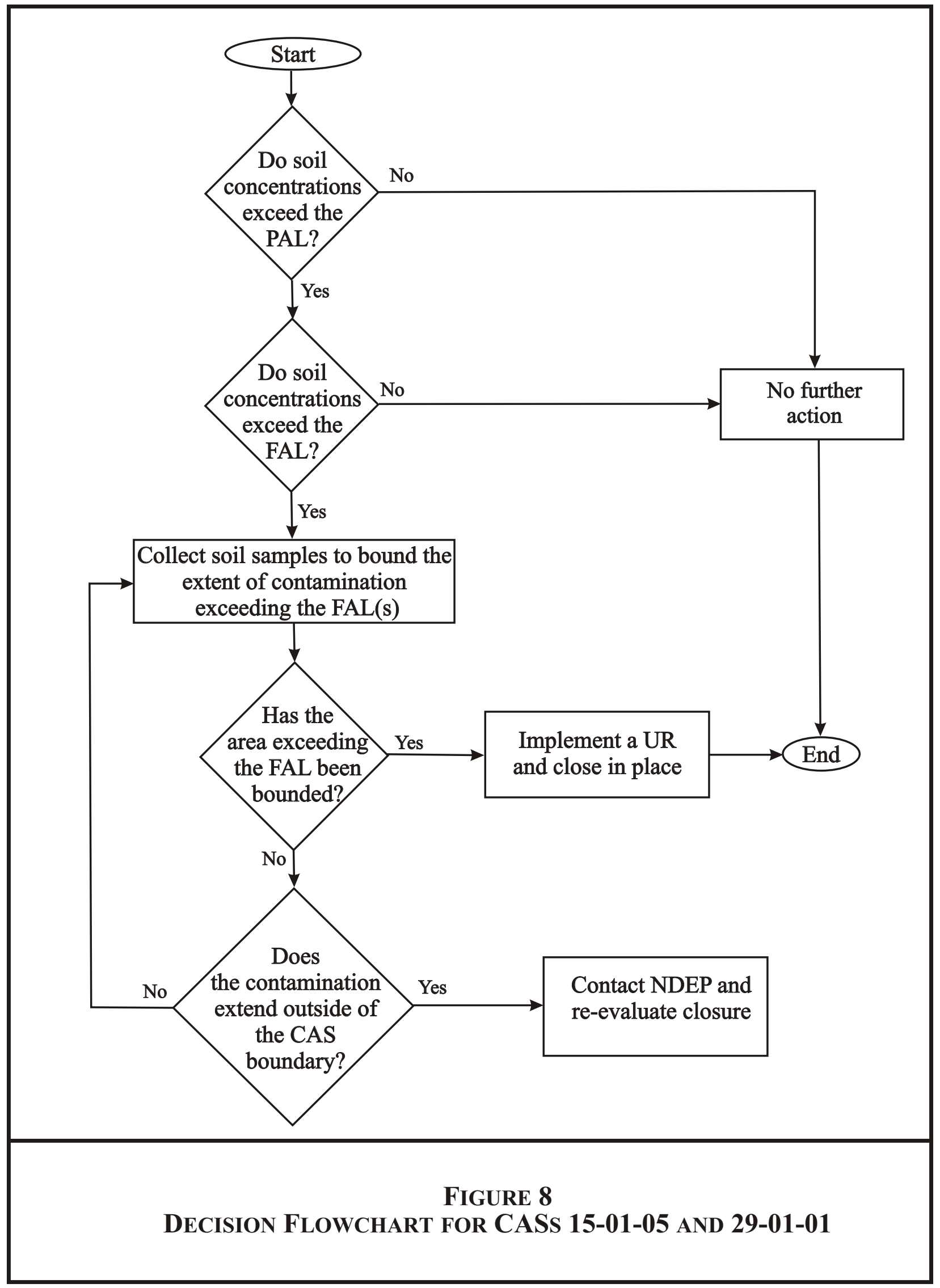




\subsubsection{HYPOTHESIS TEST}

Only valid data from laboratory analytical results will be used to determine if contamination is present. The null hypothesis is that soil below the ASTs at CASs 15-01-05 (including the original tank location) and 29-01-01 is not impacted at concentrations above action levels. The two types of decision errors are false positive and false negative.

A false positive decision error would occur if contamination is determined to be present above the action level when, in actuality, it is not. This would result in increased costs for unnecessary sample collection and analysis and post-closure costs.

A false negative decision error would occur if contamination is determined to not be present above the action level when, in actuality, it is present. If the area with contaminated soil is not identified, it would result in an increased risk to human health by leaving the impacted soil in place without identifying the hazard through a UR.

\subsubsection{Statistical Model}

Individual sample results will be compared to action levels, and statistical models will not apply for determining the actions at the CAU 134 CASs. CASs 15-01-05 and 29-01-01 will be sampled at locations most likely impacted by releases from the tanks, as determined through biasing factors at the site.

\subsubsection{DESIGN DESCRIPTION/OPTION}

Biased (judgmental) samples will be collected from below the ASTs at CASs 15-01-05 and 29-01-01 and, if the original AST location is identified, from the original AST location at CAS 15-01-05. Sample locations will be chosen based on biasing factors observed at the time of sample collection and historical reports of staining (for CAS 29-01-01). If analytical results show that the action level has been exceeded, then a minimum of three step-out surface samples will be collected to bound the extent of surface contamination, and a minimum of one subsurface sample will be collected to bound the extent of subsurface migration of contamination. If these sites are remediated, then verification samples will be collected to confirm clean closure. Verification samples will consist of a minimum of (a) 1 sample from the base of the excavation and (b) 2 samples from the sidewall if the excavation is smaller than 1-ft diameter, or 3 samples if the excavation is larger than 1-ft diameter.

\subsubsection{CSM}

One Primary CSM, with one Alternate CSM, is presented for the CAU 134 CASs. The primary CSM for CAS 03-01-03 and CAS 15-01-05 assumes that the ASTs did not release their contents to the environment. It is supported at CAS 03-01-03 by process knowledge and radiological screening of the tank and surrounding area. The primary CSM for CAS 29-01-01 assumes that diesel fuel was released to the environment. It is supported by minor soil staining under the spigot. The alternate CSM for CAS 15-01-05 assumes the contents (some or all) have been released to the environment. Because the CAS 15-01-05 AST does not appear to have been operational in its current location, a release from this AST should have resulted in a localized release of a limited volume to the surface soil, with limited migration into the subsurface soil. The alternate CSM for CAS 29-01-01 assumes the AST did not release its contents to the environment. The primary and alternate CSMs for these CASs are presented in Figures 3 and 4. 


\subsection{FIELD ACTIVITIES AND CLOSURE OBJECTIVES}

This section provides the framework and rationale for characterization, remediation, closure verification, waste disposal, and site restoration. The SAFER Plan process is discussed in detail in the following subsections.

Prior to beginning the corrective action investigation and site closure fieldwork, the following activities will be (or have been) completed:

- Collect and review aerial photographs of the facility

- Review preliminary assessment materials and process knowledge

- Obtain additional data, as needed, to support project planning

- Prepare a National Environmental Policy Act (NEPA) Checklist

- Prepare a SSHASP or JHA

- Prepare an NNSA/NSO Real Estate/Operations Permit (REOP)

\subsection{Contaminants of Potential Concern}

\subsubsection{CAS 03-01-03}

There are no contaminants of potential concern (COPCs) for this CAS. Process knowledge is adequate.

\subsubsection{CAS 03-01-04}

There are no COPCs for this CAS. Process knowledge is adequate.

\subsubsection{CASs 15-01-05 AND 29-01-01}

No contaminants are expected at CAS 15-01-05 because it likely arrived at its current location empty and because of expected natural degradation of any contamination at the tank's original location. There is greater likelihood for the presence of contaminants at CAS 29-01-01; however, natural degradation may have also reduced remaining soil concentrations. The COPC at both sites is petroleum hydrocarbons. The full suite hydrocarbon range (gas-diesel-oil) will be investigated at CAS 15-01-05, and diesel-range petroleum hydrocarbons will be investigated at CAS 29-01-01. If the $100 \mathrm{mg} / \mathrm{kg}$ action level is exceeded at either of the sites, additional samples will be collected to identify whether VOC or SVOC components of diesel are present at concentrations greater than PRGs. Compounds at concentrations greater than the PRGs (i.e., the FALs) will become COCs.

\subsection{REMEDIATION}

\subsubsection{CAS 03-01-03, Aboveground Storage TANK}

No remediation is needed at this site. As a BMP, the tank will be screened for free-release according to the NV/YMP Radiological Control (RadCon) Manual (NNSA/NSO, 2004) and M\&OC procedures, after which it will be disposed of at an onsite disposal facility or otherwise dispositioned in accordance with applicable federal, state, and local regulations. All radiological survey instruments will be used according to M\&OC operating procedures. Surveys will be performed in accordance with approved procedures. 


\subsubsection{CAS 03-01-04, TANK}

The CAS 03-01-04 tank was used to store potable water; therefore, the tank and releases from this tank are not an environmental concern. No action will be taken at this location.

\subsubsection{CAS 15-01-05, ABoveground StORAGE TANK}

This CAS will be closed by taking the following actions:

- Identify biasing factors: Document the location of tank openings before moving the tank. The most distinguishing biasing factors expected are the locations of AST openings with respect to the ground surface, and any slope of the AST and/or ground surface (i.e., where any contents would most likely have released from the tank in its current setting). Conduct a visual inspection of the Climax Mine area to identify the original location of the AST, if any evidence of the original tank location remains at the site.

- Disposition of AST: Screen the tank for free-release according to the NV/YMP RadCon Manual (NNSA/NSO, 2004) and M\&OC procedures. All radiological survey instruments will be used according to M\&OC operating procedures. Surveys will be performed in accordance with approved procedures. The In Situ Object Counting System may also be used to verify compliance with the radioactive concentration limits for disposal at the Area 9 U10c Industrial Landfill. As a BMP, the tank will be disposed of at the appropriate facility or otherwise dispositioned in accordance with applicable federal, state, and local regulations.

- Determine if COCs are present in soil below AST: Sample soil below the AST at a location most likely to be impacted by a release from the tank (i.e., in absence of staining, at the tank opening at the lowest point of the tank). If the original tank location is found, sample soil from the area most likely impacted by a release from the tank at its original location. Analyze the sample(s) for TPH. If TPH concentrations exceed $100 \mathrm{mg} / \mathrm{kg}$, collect additional samples from the same location(s) and analyze for VOCs and SVOCs. Compare analytical results against the FALs listed in Table 2. If all COPCs are less than FALs, then no COCs are present, and no further action is required.

- Determine extent of contamination, if necessary: If sample results show that FALs have been exceeded, then collect a minimum of three surface step-out samples and analyze for those compounds that exceeded the FALs. Collect additional step-out samples as needed to determine the extent of contamination. Collect a minimum of one additional step-out sample from subsurface soil located just above the bedrock interface.

- Evaluate whether clean closure is a viable option and, if so, excavate soil exceeding action levels: If contamination is less than one cubic yard in extent and can safely be excavated, then excavate contaminated soil and collect cleanup verification samples. A minimum of (a) 1 sample from the base of the excavation and (b) 2 samples from the sidewall if the excavation is smaller than $1-\mathrm{ft}$ diameter, or 3 samples if the excavation is larger than $1-\mathrm{ft}$ diameter will be collected. Samples will only be analyzed for those compounds that exceeded the FALs.

- Implement Administrative UR, if necessary: If remaining soil concentrations are greater than FALs, the CAS will be closed in place. Post the site with UR signs and implement a UR. 


\subsubsection{CAS 29-01-01, HYDROCARBON STAIN}

This CAS will be closed by taking the following actions:

- Determine if COCs are present in soil below AST: Sample soil below the spigot on the north end of the AST, at the location previously identified as being stained and most likely to be impacted by a release from the tank. Analyze the sample for TPH. If TPH concentrations exceed $100 \mathrm{mg} / \mathrm{kg}$, collect additional samples from the same location and analyze for VOCs and SVOCs. Compare analytical results against the FALs listed in Table 2. If all COPCs are less than FALs, then no COCs are present, and no further action is required.

- Determine extent of contamination, if necessary: If sample results show that FALs have been exceeded, then collect a minimum of three surface step-out samples and analyze for those compounds that exceeded the FALs. Collect additional step-out samples as needed to determine the extent of contamination. Collect a minimum of one additional step-out sample from subsurface soil located just above the bedrock interface.

- Evaluate whether clean closure is a viable option and, if so, excavate soil exceeding action levels: If contamination is less than one cubic yard in extent and can safely be excavated, then excavate contaminated soil and collect cleanup verification samples. A minimum of (a) 1 sample from the base of the excavation and (b) 2 samples from the sidewall if the excavation is smaller than 1-ft diameter, or 3 samples if the excavation is larger than $1-\mathrm{ft}$ diameter will be collected. Samples will only be analyzed for those compounds that exceeded the FALs.

- Implement Administrative UR, if necessary: If remaining soil concentrations are greater than FALs, the CAS will be closed in place. Post the site with UR signs and implement a UR.

\subsubsection{Posting}

A UR will be implemented if the FALs are exceeded at CAS 15-01-05 or CAS 29-01-01 and cannot be clean closed. If a UR is implemented, signs will be posted in accordance with the "FFACO Use Restriction Posting Guidance for NNSA/NSO and Associate Contractors" (FFACO, 2003).

\subsection{VERIFICATION}

Verification samples will be collected only if a site is excavated to remove contamination. Conditions for which verification samples will be collected, as well as the appropriate analytical method, are detailed in Section 4.2.

All samples will be collected by qualified M\&OC personnel using standard sampling procedures. Sample collection date, time, and other pertinent information will be logged on a "Service Request and Chain of Custody Record." All samples will be collected in clean containers, labeled appropriately, sealed with a tamper-proof seal, bagged, placed on ice in a cooler, and transported to an offsite analytical laboratory following strict chain of custody. Samples will be analyzed by EPA-approved analytical methods at EPA-approved laboratories (EPA, 1996). Sample analysis will include laboratory analysis of QA/QC samples and will follow stringent QA/QC procedures (EPA, 1996). 
One set of QA/QC samples will be collected for every 20 environmental samples or with every batch of samples submitted for laboratory analysis, whichever is greater, with every group of samples submitted for laboratory analysis. QA/QC samples will include blind duplicates and matrix spike/matrix spike duplicates. The blind duplicate will be labeled with a unique sample number. If samples are collected for VOC analysis, then a corresponding trip blank will accompany the VOC samples to the analytical laboratory for analysis.

All laboratory data generated during closure activities will be reviewed by project personnel to ensure the data are usable and complete according to the CAU 134 DQOs. In addition, as specified in the Industrial Sites QAPP (NNSA/NV, 2002), a minimum of 100 percent of the final data packages for verification samples will be evaluated at the Tier I and Tier II levels for validating data. Any data determined not to be valid will be identified in the CR. More details on the proposed number and location of the verification samples are provided in Section 4.2.

\subsection{Closure}

Specific activities required to close CAU 134 are described in Section 4.2. Hold points and special conditions that may be outside the initial project assumptions of this SAFER Plan may impact the requirements for closure. General closure activities include the following:

- Identify biasing factors

- Plan for remediation and disposal activities

- Perform site setup and prepare for field activities (including mitigation of safety hazards)

- Provide for final disposition of ASTs

- Determine if COCs are present in soil

- Determine the extent of contamination exceeding action levels, if any

- Install final site postings and URs, as necessary

- Complete project closeout, including preparation and submittal of a CR to the NDEP for approval

Upon receiving approval of the CR from NDEP, the NNSA/NSO will request promotion of CAU 134 to Appendix IV of the FFACO, "Closed Corrective Action Units."

\subsection{DuRATION}

Closure activities for CAU 134 are scheduled to be completed during FY 2009. The schedule will require modifications if conditions exist that are outside the assumptions on which this SAFER Plan was developed. All attempts will be made to conduct work in a manner that maximizes safety and efficiencies (e.g., some activities may occur concurrently) and minimizes the amount of personnel required to complete closure activities. Table 3 presents the proposed project schedule. 


\section{Table 3. Project Schedule}

\begin{tabular}{|l|c|l||}
\hline \multicolumn{1}{|c|}{ PROJECT PHASES } & $\begin{array}{c}\text { DURATION } \\
\text { (Calendar Days) }\end{array}$ & \multicolumn{1}{c|}{ ACTIVITIES } \\
\hline \hline Field Planning & 60 days & $\begin{array}{l}\text { Develop work packages, NEPA checklist, REOP, and other field } \\
\text { planning documents. Obtain equipment and supplies needed for sample } \\
\text { collection. Identify biasing factors. }\end{array}$ \\
\hline Field Preparation & 14 days & $\begin{array}{l}\text { Brief field support personnel. Mobilize equipment and supplies, post } \\
\text { work areas, set up waste accumulation areas, if needed. }\end{array}$ \\
\hline Field Execution & 30 days & Complete the field activities as identified in this plan. \\
\hline Sample Analysis & 30 days & Complete laboratory analysis of samples and data validation. \\
\hline Field Execution & 60 days & $\begin{array}{l}\text { If needed, collect step-out samples to identify extent of contamination } \\
\text { and post UR(s). }\end{array}$ \\
\hline Sample Analysis & 30 days & Complete laboratory analysis of step-out samples and data validation. \\
\hline Waste Management & 21 days & Dispose of generated waste at the appropriate facility/facilities. \\
\hline SAFER CR & 140 days & Prepare CR, review, and receive approval. \\
\hline \hline
\end{tabular}


SAFER Plan - CAU 134

Section: Field Activities

Revision: 0

Date: May 2008

THIS PAGE INTENTIONALLY LEFT BLANK 


\subsection{REPORTS AND RECORDS AVAILABILITY}

This document is available in the NNSA/NSO public reading facilities located in Las Vegas and Carson City, Nevada, or by contacting the appropriate NNSA/NSO Federal Sub-Project Director. The NDEP maintains the official Administrative Record for all activities conducted under the auspices of the FFACO. These documents will be onsite and referred to as necessary to perform work in a safe and orderly manner. Prior to beginning closure activities, several work control processes must be implemented.

\subsection{Field Management Plan}

A Field Management Plan (FMP) will be prepared prior to beginning closure activities. The FMP will outline the schedule for the project, and will indicate how safety will be integrated into the work management and how the field activities will be accomplished. In addition, the FMP will identify the responsible parties for each aspect of the project and will indicate how decisions will be made. Copies of the FMP will be available at the work site and will be on file in the M\&OC Environmental Restoration (ER) offices in Mercury, Nevada.

\subsection{National Environmental Policy act Checklist}

A NEPA Checklist will be completed prior to all field activities where contact work is performed. Field activities will follow all applicable federal, state, and local laws, regulations, and permits regarding protection of the environment.

\subsection{DAILY FIELd REPORTS}

A detailed Daily Field Report will be compiled to document activities that have been completed, identify any issues, and report how each issue was, or is being, resolved. This report will be provided to the M\&OC ER Task Manager who will communicate the progress of the field activities to the NNSA/NSO Task Manager.

The NNSA/NSO Task Manager will act as a liaison to the NDEP oversight staff member and provide any requested additional field information. Copies of the reports and support documentation will be filed in the M\&OC ER offices in Mercury, Nevada.

\subsection{Radiological SURVEY RePORTS}

Radiological survey reports, log entries, or other documentation deemed appropriate by RadCon, will be completed for radiological surveys performed during closure of CAU 134. A few examples and reasons for performing radiological surveys include:

- Characterization surveys (i.e., waste, contaminated surfaces)

- Verification surveys

- Free release of items or equipment

Radiological surveys will be appropriately conducted and documented by Radiological Control Technicians. Typical survey information includes fixed and transferable contamination levels, exposure rates, and any other information deemed appropriate by the survey generator. All 
radiological survey data will be reviewed by M\&OC RadCon Supervision. Copies of the radiological survey reports and support documentation will be filed in the M\&OC ER offices in Mercury, Nevada. Final verification surveys will be included in the CR.

\subsection{Closure Report}

Upon completion of the approved closure activities, a CR will be prepared and submitted to NDEP for approval. The CR will include all the sections required by the approved FFACO outline for the CR. In general, the CR will include the following sections:

- Introduction (purpose and scope)

- Closure activities (description of corrective action activities, deviations from the SAFER Plan as approved, corrective action schedule as completed, and site plan/survey plan)

- Waste disposition

- Closure verification results (data quality assessment and URs)

- Conclusions and recommendations

- References

- Supporting documentation (sample analytical results, summary of radiological survey data, waste disposition documentation, and modifications to the SAFER Plan)

This SAFER Plan and the subsequent CR will be available in the NNSA/NSO public reading facilities in Las Vegas and Carson City, Nevada, or by contacting the NNSA/NSO Federal Sub-Project Director. 


\subsection{INVESTIGATION/REMEDIATION WASTE MANAGEMENT}

All waste will be managed and disposed of in accordance with applicable federal and state regulations, U.S. Department of Energy orders, U.S. Department of Transportation regulations, and applicable M\&OC procedures. CAU 134 closure activities are expected to generate sanitary waste, construction debris, and possibly hydrocarbon waste. Waste generated during closure activities will be properly managed and shipped to onsite or offsite disposal facilities. All waste shipment and transportation documentation will be maintained in the project files. If final waste disposition occurs prior to the final CR being submitted, the documentation will be included in the CR. If shipment occurs after the CR is submitted, then the documentation will be maintained in the project files.

\subsection{Waste Minimization}

All work activities that generate waste will follow the M\&OC Waste Minimization and Pollution Prevention Program. Special care will be taken to properly characterize and segregate the waste streams to avoid the generation of additional waste.

\subsection{Potential Waste Streams}

Only sanitary waste is expected to be generated during the closure of CAU 134. Waste streams that will be generated during closure will be sufficiently characterized to facilitate proper disposal. Waste streams that will be generated and that may be generated are discussed in the following sections.

\subsubsection{SANitARY WASTE}

Nonhazardous, solid waste items expected to be generated during CAU 134 closure consist of ASTs and/or their contents, non-impacted personal protective equipment, and general trash. All sanitary waste that is surveyed by RadCon and determined not to be radiologically impacted above the surface and mass concentrations for the Area 9 U10c Industrial Landfill for free release (NNSA/NSO, 2004) will be disposed of in an onsite landfill.

\subsubsection{HYDROCARBON WASTE}

Although generation of hydrocarbon-contaminated soil is not planned, petroleum hydrocarbon waste could be present and generated from CASs 15-01-05 or 29-01-01. All hydrocarbon waste will be field-screened to verify that it is not radiologically impacted and that it meets the free release criteria for disposal and can be disposed of at the Area 6 Hydrocarbon Landfill or, for limited quantities of hydrocarbon-impacted waste, at the Area 9 U10c Industrial Landfill. 
SAFER Plan - CAU 134

Section: Investigation/Remediation

Revision: 0

Date: May 2008

THIS PAGE INTENTIONALLY LEFT BLANK 


\subsection{QUALITY ASSURANCE/QUALITY CONTROL}

The overall objective of the closure activities described in this SAFER Plan is to collect accurate and defensible data to support the closure activities for CAU 134. Data will be collected in the form of radiological surveys, TPH field screening, and sample analytical results. Proper characterization and management of the waste streams produced during closure of CAU 134 will be verified by laboratory analysis.

\subsection{Sample Collection Activities}

For CASs 15-01-05 and 29-01-01, samples will be collected from biased sample locations, in the locations most likely to be impacted by releases from the AST. Specific sample locations and the rationale for those sample locations are presented in Section 4.2.

All samples will be collected by qualified M\&OC personnel using standard sampling procedures. Sample collection date, time, and other pertinent information will be logged on an "Analytical Laboratory Service Request and Chain of Custody Report." All samples will be collected in clean containers, labeled appropriately, sealed with a tamper-proof seal, bagged, placed on ice in a cooler, and transported to an offsite analytical laboratory following strict chain of custody. Samples will be analyzed by EPA-approved analytical methods at EPA-approved laboratories (EPA, 1996). Sample analysis will include laboratory analysis of QA/QC samples and will follow stringent QA/QC procedures (EPA, 1996).

One set of QA/QC samples will be collected for every 20 environmental samples or with every batch of samples submitted for laboratory analysis, whichever is greater. QA/QC samples will include blind duplicates and matrix spike/matrix spike duplicates. The blind duplicate will be labeled with a unique sample number. All samples will be collected in accordance with the Industrial Sites QAPP (NNSA/NV, 2002). If samples are collected for VOC analysis, a trip blank will accompany each batch of VOC samples and will be analyzed in accordance with the QAPP.

\subsection{ApPlicable Laboratory/Analytical Data Quality Indicators}

A quantitative measurement of COCs is required to determine the proper closure alternative for each site. Defensible laboratory analytical results are needed for this decision-making process. Rigorous QA/QC that will be implemented for all samples includes documentation, data verification, validation of analytical results, and meeting the requirements of DQIs as they relate to laboratory analysis.

Analytical results will be verified and validated according to established procedures and with the requirements specified in this SAFER Plan. All laboratory data from sampling activities will be evaluated for data quality according to EPA Functional Guidelines and DQOs. The data will be reviewed to ensure that all critical samples were appropriately collected and analyzed and that the results passed data validation criteria. Validated data, whether estimated or not, will be assessed to determine if they meet the DQOs of the investigation and the performance criteria for the DQIs. The results of this assessment will be documented in the CR. If the DQOs are not met, corrective actions will be evaluated, selected, and implemented (e.g., refine CSM or re-sample to fill data gaps). 
DQIs are qualitative and quantitative statements that specify the data requirements of a project. The DQIs for CAU 134 include precision, accuracy/bias, representativeness, comparability, completeness, and sensitivity. These DQIs are discussed in the following sections and summarized in Table 4. Any deficiencies noted during the investigation that render the data quality unacceptable will be documented in the CR.

\subsubsection{PRECISION}

Precision measures the reproducibility of data under a given set of conditions. It is a quantitative measurement of the variability of a population of measurements compared to their average value. Precision applies to parameters sampled and analyzed in duplicate.

Precision will be assessed by collecting one duplicate sample for every 20 regular samples. Duplicate samples will be collected and analyzed for each medium and analyte. Analytical precision will be monitored through analysis and evaluation of laboratory duplicates.

\subsubsection{ACCURACY/BIAS}

Accuracy is a measure of the closeness of an individual measurement or the average of a number of measurements to the true value. Accuracy includes a combination of random error (precision) and systematic error (bias) components that result from sampling and analytical operations. This closeness is expressed as percent recovery (\%R) (EPA, 1996). Accuracy will be assessed by examining the $\% \mathrm{R}$ of laboratory control and spiked samples. A $\% \mathrm{R}$ within the range of 70 to 130 percent indicates satisfactory analytical accuracy (NNSA/NV, 2002).

\subsubsection{REPRESENTATIVENESS}

Representativeness is a qualitative measure of the degree to which the sample data accurately and precisely represent a characteristic of a sample population or environmental condition. Representativeness will be attained by ensuring that the sample locations, analytical parameters, analytical methods, sampling protocols, and sample handling all meet the project-specific objective.

\subsubsection{COMPARABILITY}

Comparability is a qualitative measure that expresses the confidence that one data set can be compared to another. It will be achieved by adhering to the standardized field sampling procedures. The same analytical laboratory will perform the same analyses for all samples. All samples will be collected using M\&OC standard methods of sample collection. Sample results will be reported in standard units to allow for comparison of the data.

\subsubsection{COMPLETENESS}

Completeness is a quantitative measure of data quality expressed as the percentage of valid data obtained that satisfies the project-specific requirements. Since a limited number of samples will be collected to identify whether COCs are present, 100 percent of the data collected must be of acceptable quality. Additional samples will be collected, if needed, to obtain a set of data that meets the completeness quality objective. 


\section{TABLE 4. LABoratory/Analytical Data Quality IndiCATORS}

\begin{tabular}{|c|c|c|}
\hline $\begin{array}{l}\text { DATA QUALITY } \\
\text { INDICATOR }\end{array}$ & Performance Criteria & $\begin{array}{l}\text { IMPACT ON DECISION IF PERFORMANCE } \\
\text { CRITERIA NOT MET }\end{array}$ \\
\hline Precision & $\begin{array}{l}\text { Variations between duplicates (field and lab) } \\
\text { and original sample should not exceed } \\
\text { analytical method-specific criteria. }\end{array}$ & $\begin{array}{l}\text { Estimated data within sample delivery group } \\
\text { (SDG) will be evaluated for their usability. If } \\
\text { data are determined to be unusable, data will not } \\
\text { be used in decision and completeness criteria will } \\
\text { be assessed. }\end{array}$ \\
\hline Accuracy/bias & $\begin{array}{l}\text { Laboratory control sample results and matrix } \\
\text { spike results should be within analytical } \\
\text { method-specific criteria. }\end{array}$ & $\begin{array}{l}\text { Estimated data within SDG will be evaluated for } \\
\text { its usability. If estimated data are biased high or } \\
\text { conservative, the data may be used in decision. } \\
\text { If estimated data are biased low and below the } \\
\text { decision threshold, the data may not be used in } \\
\text { decision and completeness criteria will be } \\
\text { assessed. }\end{array}$ \\
\hline Representativeness & $\begin{array}{l}\text { Correct analytical method performed for } \\
\text { appropriate COCs: valid data reflects } \\
\text { appropriate target population. }\end{array}$ & $\begin{array}{l}\text { Cannot identify COCs or estimate concentration } \\
\text { of COCs; therefore, cannot make decision(s) on } \\
\text { target population. }\end{array}$ \\
\hline Comparability & $\begin{array}{l}\text { Equivalent samples analyzed using same } \\
\text { analytical methods, same units of } \\
\text { measurement, and detection limits for like } \\
\text { analyses. }\end{array}$ & Inability to use data collected. \\
\hline Completeness & $\begin{array}{l}100 \% \text { of samples submitted to laboratory } \\
100 \% \text { of requested analyses performed } \\
100 \% \text { of critical analytes to be valid }{ }^{\mathrm{a}}\end{array}$ & $\begin{array}{l}\text { 1. Decision of whether COC is present cannot be } \\
\text { determined. } \\
\text { 2. Decision of whether extent of contamination } \\
\text { has been bounded cannot be determined. } \\
\text { Impacts to decisions will be assessed. } \\
\text { 3. Decision of whether COCs above action levels } \\
\text { remain in soil cannot be determined. Impacts } \\
\text { to decisions will be assessed. }\end{array}$ \\
\hline Sensitivity & $\begin{array}{l}\text { Detection limits of laboratory instruments } \\
\text { must be less than action level for COC. }\end{array}$ & $\begin{array}{l}\text { Cannot determine if COCs are present at levels of } \\
\text { concern, thereby investigation objectives cannot } \\
\text { be met. }\end{array}$ \\
\hline
\end{tabular}

Source: Industrial Sites QAPP (NNSA/NV, 2002)

${ }^{a}$ Critical analytes are those analytes most likely present in the target population as COCs, which have been identified through process knowledge of similar sites and historical documentation. 


\subsubsection{SENSITIVITY}

Sensitivity is the capability of a method or instrument to discriminate between measurement responses representing different levels of a variable of interest. This indicator is determined from the value of the standard deviation at the concentration level of interest. It represents the minimum difference of concentration that can be distinguished between two samples with a high degree of confidence. Sensitivity must be sufficient to detect contaminants at or below decision levels. Sensitivity will be achieved by analyzing all samples using the appropriate analytical laboratories, methods, and instruments. 


\subsection{REFERENCES}

Air Resources Laboratory, Special Operations and Research Division. 2004. "Air Resources Laboratory/Special Operations and Research Division” Web Site. Available at http://www.sord.nv.doe.gov/ar/sord-1.htm [Accessed October 6, 2004].

DOE/NV, see U.S. Department of Energy, Nevada Operations Office

EPA, see U.S. Environmental Protection Agency.

Federal Facility Agreement and Consent Order. 1996 (as amended February 2008). Agreed to by the state of Nevada; the U.S. Department of Energy, Environmental Management; the U.S. Department of Defense; and the U.S. Department of Energy, Legacy Management.

Federal Facility Agreement and Consent Order. 2003. "FFACO Use Restriction Posting Guidance for NNSA/NSO and Associated Contractors."

FFACO, see Federal Facility Agreement and Consent Order.

Haworth, O. L., Reynolds Electrical \& Engineering Company, Inc. 1991. Memorandum to J. D. Stewart (U.S. Department of Energy, Nevada Operations Office) entitled, "Environmental Compliance Office (ECO) Activity Report for July 1991," August 27, 1991. Las Vegas, NV.

Henderson, R., Los Alamos National Laboratory. 2007. Record of Telecommunication with A. Urbon (National Security Technologies, LLC) regarding the CAS 03-01-03 mud tank, December 20. Mercury, NV.

Holmes and Narver, Inc. 1967a. As-built engineering drawing JS-002-U3em-M1.1 entitled, "Nevada Test Site - Area 3 Mud Tank - Sta U3em Plan \& Elevation," November 10, 1967. Mercury, NV.

Holmes and Narver, Inc. 1967b. Engineering drawing JS-003-U3em-C1.8 entitled, "Nevada Test Site - Area 3 Surface Facilities - Sta. U3em Site Plan,” May 1, 1967. Mercury, NV.

Holmes and Narver, Inc. 1967c. Engineering drawing JS-003-U3em-S14.1 entitled, "Nevada Test Site - Area 3 Concrete Fdn.-Mud Tank - Sta. U3em Plan, Elev., Section \& Det.," September 20, 1967. Mercury, NV.

Holmes and Narver, Inc. 1967d. As-built engineering drawing 003-850-C1.2 entitled, "Nevada Test Site - Area 3 - Station 850 Core Handling Building Plot Plan,” April 20, 1967. Mercury, NV.

Holmes and Narver, Inc. 1967e. As-built engineering drawing 003-850-M1.1 entitled, "Nevada Test Site - Area 3 - Station 850 Core Handling Building Utilities - Plan \& Details," June 18, 1967. Mercury, NV.

Holmes and Narver, Inc. 1967f. As-built engineering drawing 003-850-S2 entitled, "Nevada Test Site - Area 3 - Station 850 Core Handling Building Plan \& Sections," April 18, 1967. Mercury, NV.

NAC, see Nevada Administrative Code.

Nevada Administrative Code. 2006. NAC 445A.2272, "Contamination of soil: Establishment of action levels." Carson City, NV. 


\subsection{REFERENCES (continued)}

NNSA/NSO, see U.S. Department of Energy, National Nuclear Security Administration Nevada Site Office.

NNSA/NV, see U.S. Department of Energy, National Nuclear Security Administration Nevada Operations Office.

Radack, P. 1999. "Shoshone Mountain tank," Email to J. Appenzeller-Wing. November 24, 1999. Las Vegas, NV.

REECo, see Reynolds Electrical and Engineering Company, Inc.

Reynolds Electrical and Engineering Company, Inc. 1991. Nevada Test Site Inventory of Inactive and Abandoned Facilities and Waste Sites. DOE/NV/10630-18. April 1991. Las Vegas, NV.

U.S. Department of Energy, National Nuclear Security Administration Nevada Operations Office. 2002. Industrial Sites Quality Assurance Project Plan, Revision 3, DOE/NV--372-REV 3, Las Vegas, NV.

U.S. Department of Energy, National Nuclear Security Administration, Nevada Site Office. 2004. NV/YMP Radiological Control Manual. DOE/NV/11718-079 Rev. 5. Las Vegas, NV.

U.S. Department of Energy, Nevada Operations Office. 2000a. Corrective Action Investigation Plan for Corrective Action Unit 97: Yucca Flat/Climax Mine, Nevada Test Site, Nevada. DOE/NV--659. Las Vegas, NV.

U.S. Department of Energy, Nevada Operations Office. 2000b. United States Nuclear Tests July 1945 through September 1992. DOE/NV--209-Rev 15, Las Vegas, NV.

U.S. Environmental Protection Agency. 1996. Test Methods for Evaluating Solid Waste Physical/Chemical Methods. SW-846, 3rd Edition. Washington, D.C.

U.S. Environmental Protection Agency. 2004. Region IX Preliminary Remediation Goals. San Francisco, CA.

U.S. Environmental Protection Agency. 2006. Guidance on Systematic Planning Using the Data Quality Objectives Process. EPA QA/G-4. Washington, D.C. 
SAFER Plan - CAU 134

Section: Appendix A

Revision: 0

Date: May 2008

\section{APPENDIX A. PROJECT ORGANIZATION}


SAFER Plan - CAU 134

Section: Appendix A

Revision: 0

Date: May 2008

THIS PAGE INTENTIONALLY LEFT BLANK 


\section{PROJECT ORGANIZATION}

The U.S. Department of Energy, National Nuclear Security Administration Nevada Site Office (NNSA/NSO) Federal Sub-Project Director is Kevin Cabble, and his telephone number is (702) 295-5000.

The identification of the project Health and Safety Officer and the Quality Assurance Officer can be found in both the Field Management Plan and either the Site-Specific Health and Safety Plan or Job Hazard Analysis. However, personnel are subject to change, and it is suggested that the appropriate NNSA/NSO Federal Sub-Project Director be contacted for further information. The Task Manager will be identified in the Federal Facility Agreement and Consent Order Monthly Activity Report prior to the start of field activities. 
SAFER Plan - CAU 134

Section: Appendix A

Revision: 0

Date: May 2008

THIS PAGE INTENTIONALLY LEFT BLANK 


\section{LIBRARY DISTRIBUTION LIST}


SAFER Plan - CAU 134

Section: Distribution List

Revision: 0

Date: May 2008

\section{THIS PAGE INTENTIONALLY LEFT BLANK}




\section{LIBRARY DISTRIBUTION LIST}

U.S. Department of Energy

National Nuclear Security Administration

Nevada Site Office

Technical Library

P.O. Box 98518, M/S 505

Las Vegas, NV 89193-8518

U.S. Department of Energy

Office of Scientific and Technical Information

P.O. Box 62

Oak Ridge, TN 37831-0062

Southern Nevada Public Reading Facility

c/o Nuclear Testing Archive

P.O. Box 98521, M/S 400

Las Vegas, NV 89193-8521

Manager, Northern Nevada FFACO

Public Reading Facility

c/o Nevada State Library \& Archives

Carson City, NV 89701-4285
1 (Uncontrolled, electronic copy)

1 (Uncontrolled, electronic copy)

2 (Uncontrolled, electronic copies)

1 (Uncontrolled, electronic copy) 
Revision: 0

Date: May 2008

THIS PAGE INTENTIONALLY LEFT BLANK 